\title{
The formability of twinning - induced plasticity steels predicted on the base of Marciniak-Kuczynski theory
}

\author{
Marilena C. Butuc ${ }^{1}$, Frederic Barlat ${ }^{2}$ and Gabriela Vincze ${ }^{1}$ \\ ${ }^{1}$ Center for Mechanical Technology and Automation (TEMA), Department of Mechanical \\ Engineering, University of Aveiro, Portugal \\ ${ }^{2}$ Graduate Institute of Ferrous Technology (GIFT), Pohang University of Science and Technology \\ (POSTECH), South Korea
}

\begin{abstract}
The purpose of this work is to predict and analyze the formability of twinning - induced plasticity steels through the Marciniak-Kuczynski (MK) theory with emphasis on the solutions for improving the prediction results. The selected constitutive equations involve the Yld00-2d of Barlat et al. (2003) plane stress yield function, the Swift strain-hardening power law and the dislocation density based constitutive model proposed by Kim et al. (2013), taking into account the dislocation glide, twinning and dynamic strain aging. Three types of high manganese content TWIP steels sheet were selected. To understand the formability of the TWIP steel and the factors influencing it, a sensitive study on the effect of the mechanical properties of the TWIP steel on the MK theory concept and the predicted forming limits is performed. Using the dislocation density based microstructural model, the deformation twinning effect and the contribution of dynamic strain aging to the FLDs of TWIP steel is analyzed. The relevant influence of the sharpness of the yield surface in the biaxial stretching region in the prediction of FLDs of TWIP steels is highlighted. The extended MK model can be adapted to predict the forming limits of the TWIP steels by using an unusual high initial geometrical defect imposed by their high strain hardening. In this way it was showed that the MK theory cannot be applied for predicting the forming limits of TWIP steels unless by applying imperfection factors that are not physically reasonable. Therefore, new failure models are required for TWIP steel.
\end{abstract}

Keywords: Formability; TWIP steels; Constitutive equations; Yield condition; Dislocationbased hardening, M-K model; Numerical simulation. 


\section{Introduction}

The advanced high-strength steels (AHSS) are valuable materials for the automotive industry, for developing lightweight vehicle bodies with superior crash-energy management capabilities. High Mn Twinning-Induced Plasticity (TWIP) steel is a structural steel of second generation of AHSS with a high strength and a superior formability attained due to the high rate of strain hardening associated with the deformation-twinning phenomenon. The high ductility and strength of these lightweight TWIP steels could improve the crash resistance of structural car body parts, according to Grässel et al. (2000). These excellent properties of the TWIP steel can lead to important weight reduction in automotive and aerospace structures, which, in turn, can translate into significant waste reduction and energy savings. The high costs of production of TWIP steel, partly due to their high Mn content, require an optimum use of the material as a priority. The failure in AHSS steels has become a challenge for the steel and automotive industry. Consequently, there is a great interest for the numerical predictions of the ductile failure of AHSS.

The sheet metal formability is limited by the occurrence of plastic flow localization, instability and fracture. The Forming Limit Diagram method, introduced by Keeler (1965) and Goodwin (1968), is the most advanced concept and current applied in industry to characterize the formability of sheet metals. Yoshida (1968) and Keeler (1965) paid attention to one of the greatest problems involved on the FLD's determination: "Must the FLD be defined in terms of fracture or localised necking?" As Coll (2000) mentioned, fracture is a well-defined criterion, easily to detect, without ambiguity, but when it occurs, it is too late and the measurement of the strains is very difficult, if not impossible. Therefore, it is more useful to predict the onset of localized necking, which in fact, decides the correctness of the work-piece. Two failure modes, namely the onset of diffuse necking and the pronounced plastic flow localization, were analyzed. Even if the second criterion is clearly visible, the strain measurement is as difficult as that of fracture, and the pronounced necking can expand over a significant range of strain. The state of onset of diffuse necking corresponds to the load instability. It is very well defined but it is too conservative for an optimum use of the material formability. According to Barata da Rocha et al. (1984), in industrial stampings the maximum allowable straining is not determined by diffuse but by localized necking. Regarding AHSS steels a new situation is emerging, since the fracture may occur with little or no post-uniform necking. Butz et al. (2013) stated that for materials which show multiple local necking or strain distributions that do not match an inverse parabola, as specified in the 
standardized cross method section of ISO 12004-2, the time-dependent method was recently developed. Over the years, the forming limit diagram concept was validated as an indispensable tool for material selection, design and try-out of the tools for deep drawing operations. Forming limits of sheet metals are influenced by several physical factors of which the most important ones are material work-hardening, strain rate sensitivity, plastic anisotropy, the development of structural damage and strain path. It is difficult to experimentally assess the influence of each parameter individually since it is virtually impossible to change only one at a time. The theoretical analysis of plastic instability and flow localization may supply relevant information to prevent the failure on the sheet metal forming process, to examine the influence of each parameter on the necking occurrence and to improve the press performance. The Marciniak-Kuczynski (1967) method has become one of the most important tools in predicting the sheet metal formability. Butuc et al., (2003) and Stoughton and Zhu, (2004) showed that the predicted limit strains strongly depend on the constitutive law incorporated in the $\mathrm{M}-\mathrm{K}$ analysis. The combination of the MarciniakKuczynski theory with accurate constitutive models is an efficient device in the understanding of material behavior and predicting the formability. In the last years, more sophisticated material models describing new generations of sheet metals have been developed.

In order to reproduce and explain the pronounced work-hardening of TWIP steel various models have been developed. Bouaziz and Guelton (2001) proposed a microstructural model of TWIP steel behavior based on the interaction between dislocation glide and deformation twinning. The model predictions were in good agreement with experimental tensile tests confirming that twins provide effective obstacles to dislocation motion. Allain et al. (2004) proposed a physical model of the twinning-induced plasticity effect in high manganese austenitic steel. They introduced the formation of mechanical microtwins in a viscoplasticity framework based on dislocation glide at the mesoscopic scale. The important aspect of this model is the rapid reduction of the dislocation mean free path between twins, which explains the high hardening rate as a dynamic Hall-Petch-like effect. Based on experimental data related to grain size and Bauschinger effects obtained from high-manganese austenitic TWIP steel, Bouaziz et al. (2007) showed a strong contribution of kinematic hardening to the mechanical behaviour. They developed an improved physical-based model describing the isotropic and the kinematic hardening contributions and validated in relation to the grain size and the twin spacing during straining. Kang et al. (2015) employed a constitutive model for 
TWIP steels, which predicts the dislocation density evolution taking into account the temperature and alloy composition. Vinogradov et al., (2017) developed a model of deformation twinning based on the idea that twin generation is a stress-driven process. Using simple assumptions regarding the grain size distribution, they proposed an equation for the variation of the twin volume fraction with the flow stress.

Concerning the formability of TWIP steels, only few researches analysed the fracture and necking mechanics of TWIP steel. Lou et al. (2012) proposed a ductile fracture criterion based on the effect of the non-dimensional stress triaxiality, the stress concentration factor and the effective plastic strain on the nucleation, growth and coalescence of voids. Habibi et al. (2015) found that a combined model based on a ductile fracture criterion incorporating the effect of the maximum shear stress e.g., the model proposed by Han and Kim (2003) and Lou et al. (2012), is more proper to predict the forming limit diagram at fracture for TWIP steel. Butz et al. (2014) developed a simulation framework to model the complex deformation and forming behaviour of TWIP steels. They modified the microstructure-based Bouaziz-Allain model and developed an extended three-dimensional finite elasto-plastic formulation.

The present work aimed at analyzing the ability of the MK model to predict the formability and failure of TWIP steels sheets. For this purpose, this study was devoted to the next topics: (i) simulation of the forming limits of the selected TWIP steel sheets using a software based on Marciniak-Kuczynski (MK) model; (ii) a meticulous analysis of the effect of the mechanical properties of TWIP steel on the predicted forming limits; (iii) searching solutions for improving the accuracy of the numerical results. In the MK model, proper constitutive equations, namely Yld00 yield function of Barlat et al. (2003), Swift hardening law and the dislocation density based constitutive model proposed by Kim et al. (2013) were considered. The identification of the parameters of the material models was performed for the selected TWIP steels. For validation of the model, experimental and the theoretical forming limit curves are compared.

\section{Review of the selected constitutive equations}

\subsection{Hardening models}

\subsubsection{Dislocation density based hardening model}

The dislocation density based hardening model (acronym DD_model) proposed by Kim et al. (2013) is based on the Kubin-Estrin model, in which the densities of mobile and forest 
dislocations are coupled in order to account for the interaction between the two dislocation populations during straining. These coupled dislocation densities were used for simulating the contribution of dynamic strain aging (DSA) to the flow stress. The model includes the effect of twinning. According to Kim et al. (2013) this modeling approach demonstrated that: (i) Grain size and dynamic recovery effects play important roles in the strain hardening behavior of twin-free grains; (ii) The deformation twins, which act as effective barriers to dislocation motion are the predominant elements of the microstructure that governs the strain hardening of the twinned grains; (iii) DSA is a minor contributor to strain hardening.

For the twin-free grains, the original coupled differential equations of the Kubin-Estrin model, presented in Estrin and Kubin(1986) and Kubin and Estrin(1990), corrected for the grain size effect, were used:

$$
\begin{aligned}
& \frac{d \rho_{m}}{d \varepsilon_{g}}=M\left[\frac{C_{1}}{b^{2}}\left(\frac{\rho_{f}}{\rho_{m}}\right)-C_{2} \rho_{m}-\frac{C_{3}}{b} \sqrt{\rho_{f}}-\frac{\xi}{b d}\right] \\
& \frac{d \rho_{f}}{d \varepsilon_{g}}=M\left[C_{2} \rho_{m}+\frac{C_{3}}{b} \sqrt{\rho_{f}}-C_{4} \rho_{f}\right]
\end{aligned}
$$

where $\varepsilon_{\mathrm{g}}$ is the plastic strain associated with dislocation glide only, $\mathrm{d}$ is the average grain size, and $b$ is the magnitude of the Burgers vector. These coupled differential equations represent the evolution of the mobile dislocation density, $\rho_{\mathrm{m}}$, and the forest dislocation density, $\rho_{\mathrm{f}}$. The coefficients $\mathrm{C}_{1}, \mathrm{C}_{2}, \mathrm{C}_{3}$, and $\mathrm{C}_{4}$ were obtained by least square fitting of the dislocation density calculated for the twin-free grains to the experimentally measured dislocation density therein. $\mathrm{M}$ is the Taylor factor and $\xi$ is a coefficient smaller than one.

The flow stress was calculated as follows:

$$
\sigma=\sigma_{0}+M \alpha G b \sqrt{\rho}+\sigma_{D S A}
$$

The variation of the mobile and the immobilized dislocation with strain for twinned grains is:

$$
\begin{aligned}
& \frac{d \rho_{m}}{d \varepsilon_{g}}=M\left[\frac{C_{1}}{b^{2}}\left(\frac{\rho_{i}}{\rho_{m}}\right)-C_{2} \rho_{m}-\frac{C_{3}}{b} \sqrt{\rho_{i}}-\frac{\xi}{b d}-\frac{\xi}{b e} \frac{F}{1-F}\right] \\
& \frac{d \rho_{i}}{d \varepsilon_{g}}=M\left[C_{2} \rho_{m}+\frac{C_{3}}{b} \sqrt{\rho_{i}}+\frac{1}{b d}+\frac{1}{b e} \frac{F}{1-F}-C_{4} \rho_{i}\right]
\end{aligned}
$$

where $\mathrm{b}$ is the magnitude of Burgers vector, $\mathrm{d}$, the grain size, $e$ the average twin thickness and $\mathrm{F}$ the twin volume fracture. 
The DSA contribution to the flow stress $\sigma_{\mathrm{DSA}}$ is:

$\sigma_{D S A}=\chi C_{S}\left(t_{w}\right)=\chi C_{m}\left\{1-\exp \left[-\frac{\mathrm{C}_{0}}{\mathrm{C}_{\mathrm{m}}}\left(\frac{\Omega}{\bar{\varepsilon} \dot{\tau}_{c}}\right)^{\frac{2}{3}}\right]\right\}=\pi n W C_{S}$

where $\chi$ is a coefficient characterizing the strength of the dislocation-solute interaction, $\mathrm{C}_{0}$, the nominal bulk concentration of carbon, $\mathrm{C}_{\mathrm{s}}\left(\mathrm{t}_{\mathrm{w}}\right)$, the concentration of carbon segregated on the dislocations over the waiting time $\mathrm{t}_{\mathrm{w}}$ and $\mathrm{C}_{\mathrm{m}}$ is the maximum attainable solute concentration on the dislocations that depends on the binding energy $\mathrm{W}$ and temperature. The dislocation density-dependent quantity $\Omega$ corresponds to a strain that would be produced if all mobile dislocations performed a thermally activated act of breakaway from localized obstacles (forest junctions).

$\Omega \approx \frac{\rho_{m} b}{\sqrt{\rho_{f}}}$

The dislocation density evolution equations for both populations of grains, the twinned and twin-free ones, are used to calculate the flow stress for the twinned grains and the flow stress of the twin-free grains, respectively. The material flow stress is calculated using a law of mixtures:

$\sigma=f(\bar{\varepsilon}) \sigma_{\text {twinned }}+(1-f(\bar{\varepsilon})) \sigma_{\text {twin-free }}$

where $f(\varepsilon)$ is the strain-dependent fraction of the twinned grains, $\sigma_{t w i n n e d}$ is the average flow stress for the twinned grains, and $\sigma_{\text {twin-free }}$ is the flow stress of the twin-free grains.

\subsubsection{Swift hardening model}

The Swift law (acronym Swift) expresses strain hardening as a power law:

$$
\bar{\sigma}=K\left(\varepsilon_{0}+\bar{\varepsilon}\right)^{n}
$$

where $\bar{\sigma}$ is the flow stress, $\bar{\varepsilon}$ the effective plastic strain, while $K, \varepsilon_{0}$ and $n$ are material parameters.

\subsection{YLD00-2D Yield Function}

The Yld00-2d plane stress yield function of Barlat et al. (2003), introduces plastic anisotropy by using two linear transformations on the Cauchy stress tensor. It is expressed in terms of the deviatoric stress components as:

$\phi=\phi^{\prime}\left(\tilde{\boldsymbol{S}}^{\prime}\right)+\phi^{\prime \prime}\left(\tilde{\boldsymbol{S}}^{\prime \prime}\right)=2 \bar{\sigma}_{\mathrm{Y}}^{a}$ 
where $\bar{\sigma}_{\mathrm{Y}}$ is the effective stress, $a$ is an exponent connected to the crystal structure, $\phi^{\prime}$ and $\phi^{\prime \prime}$ are two isotropic functions defined by

$\phi^{\prime}\left(\tilde{\boldsymbol{S}}^{\prime}\right)=\left|\tilde{S}_{1}^{\prime}-\tilde{S}_{2}^{\prime}\right|^{a}$

$\phi^{\prime \prime}\left(\tilde{\boldsymbol{S}}^{\prime \prime}\right)=\left|2 \tilde{S}^{\prime \prime}{ }_{2}+\tilde{S}^{\prime \prime}{ }_{1}\right|^{a}+\left|2 \tilde{S}^{\prime \prime}{ }_{1}+\tilde{S}^{\prime \prime}{ }_{2}\right|^{a}$

$\tilde{S}^{\prime}$ and $\tilde{S}^{\prime \prime}$ are the linear transformations of the effective stress tensor $\boldsymbol{s}$ defined as the deviatoric part $\sigma^{\prime}$ of the Cauchy stress:

$\tilde{S}^{\prime}=C^{\prime} s, \tilde{S}^{\prime \prime}=C^{\prime \prime} s$

where $\boldsymbol{C}^{\prime}$ and $\boldsymbol{C}^{\prime \prime}$ contain the material anisotropy coefficients.

\subsection{Theoretical computation of the forming limits}

The MK-type analysis, schematically illustrated in Fig. 1, is applied to simulate the plastic instability. The model is based on the evolution of an initial defect within a thin sheet by plastic deformation. The imperfection consists of a narrow groove-like band for which the rate of thickness decrease is higher than that of the material surrounding it.

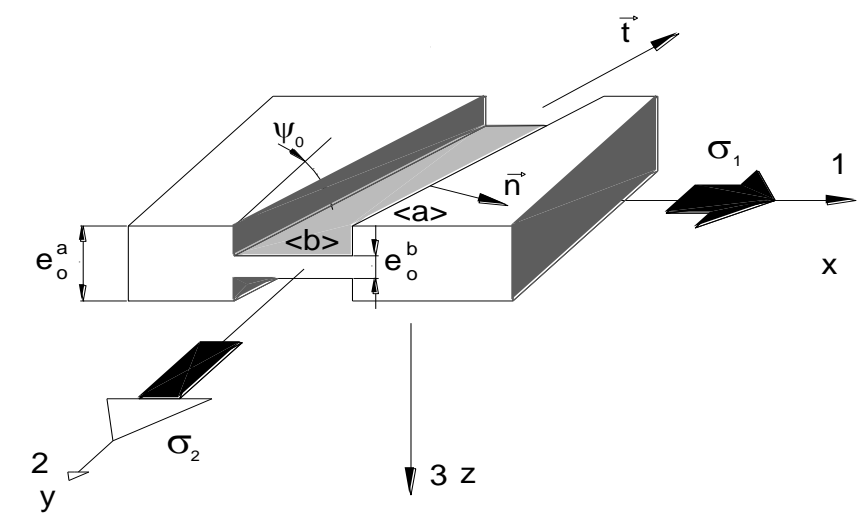

Fig. 1. Initial geometrical imperfection for the M-K analysis

Following the Hutchinson-Neal model (1978), the initial inclination angle of the band, $\psi_{0}$, with respect to the minor principal axis of the stress tensor is considered variable between $0^{\circ}$ and $90^{\circ}$ from the rolling direction. The initial value of the geometrical defect $\left(\mathrm{f}_{0}\right)$ is characterized by the ratio of the initial thickness in the homogeneous region and in the groove respectively. The $x, y, z$-axes correspond to rolling, transverse and normal directions of the sheet, while 1 and 2 represent the principal stress and strain directions in the homogeneous 
region. The set of axes bound to the groove is represented by $n, t, z$, where $t$ denotes the longitudinal axis. It is assumed that the material exhibits a rigid-plastic behavior with the initial shape of the yield locus given by the Yld00-2d plane stress yield condition. The hardening behavior of the material is approximated either by the Swift hardening law or by the selected dislocation density based hardening model mentioned above. The theoretical computation is performed using the method proposed by Butuc et al. (2011). Small increments of equivalent strain are imposed in the homogeneous region, the corresponding stress and strain states being computed according to the selected constitutive equations. The strain and stress states within the band are calculated with recourse to the Newton-Raphson method for solving a system of two polynomial equations resulting from the application of the yield criterion and the requirement of deformation compatibility in the longitudinal direction of the necking band. When the effective strain increment in the band $\left(\mathrm{d} \bar{\varepsilon}^{\mathrm{b}}\right)$ becomes 10 times larger than that in the homogeneous zone $\left(\mathrm{d} \bar{\varepsilon}^{\mathrm{a}}\right)$, it is considered that plastic flow localization occurs in the band, whereas the corresponding accumulated principal strains in the homogeneous zone define the forming limits. For each considered strain path, the analysis is repeated for different values of $\psi_{0}$ (between $0^{\circ}$ and $90^{\circ}$ ) and the limit point on the FLD is obtained through minimization with respect to $\psi_{0}$ of the principal strain $\varepsilon_{1}^{\mathrm{a}}$ in the homogeneous zone.

\subsection{Results and discussion}

\subsection{Material Characterization}

The selected materials are three high manganese content TWIP steel sheet samples, with the acronyms TWIP4EU, TWIP980 and TWIP940. The present study used the experimental data from published literature, namely the characterization of TWIP4EU from Butz et al (2014), the characterization of TWIP980 from Xu et al. (2012) and Xu and Barlat (2011) and the characterization of TWIP940 from Chung et al. (2011). Tables 1, 2 and 3 list the corresponding values for the yield stresses and anisotropy factor $R$ for three uniaxial tensile directions, the balanced biaxial yield stress $\sigma_{b}$ and the biaxial anisotropy coefficient $R_{\mathrm{b}}$. Relating to the TWIP4EU steel sheet, it is mentioned that, due of the inexistence of the experimental values, it was assumed the balanced biaxial yield stress $\sigma_{b} *$ normalized by the uniaxial yield stress at $0^{\circ}$ from rolling direction of 0,98 and the biaxial anisotropy coefficient $\mathrm{Rb}^{*}$ of 0,75 , following the experimental tendencies of TWIP980 steel sheet. The table 4 lists 
the normalized flow stresses at different amounts of specific plastic work $w$ in uniaxial tension and hydraulic bulge tests determined by Xu and Barlat (2011) in order to investigate the yield surface evolution. The selected $w$ values of 5, 50, 119 and $205 \mathrm{MPa}$ correspond to the plastic longitudinal strains of $0.01,0.08,0.16$ and 0.24 in rolling direction uniaxial tension.

Table 1. Mechanical properties of TWIP4EU steel sheet from Butz et al. (2014)

\begin{tabular}{ccccc}
\hline Orientation & $\begin{array}{c}\text { Yield stress } \\
{[\mathrm{MPa}]}\end{array}$ & $\begin{array}{c}\text { Biaxial yield } \\
\text { stress } \sigma_{\mathrm{b}}^{*}[\mathrm{MPa}]\end{array}$ & $\begin{array}{c}\text { Anisotropy } \\
\text { factor } R\end{array}$ & $\begin{array}{c}\text { Biaxial } \\
\text { anisotropy factor } \\
R_{\mathrm{b}}{ }^{*}\end{array}$ \\
\hline $0^{\circ}$ & 633 & & 0.787 & 0.75 \\
\cline { 1 - 2 } $45^{\circ}$ & 630 & 620 & 0.962 & \\
\hline $90^{\circ}$ & 652 & & 0.997 \\
\hline
\end{tabular}

Table 2. Mechanical properties of TWIP 980 steel sheet from Xu et al. (2012)

\begin{tabular}{ccccc}
\hline Orientation & $\begin{array}{c}\text { Yield stress } \\
{[\mathrm{MPa}]}\end{array}$ & $\begin{array}{c}\text { Biaxial yield } \\
\text { stress } \sigma_{\mathrm{b}}[\mathrm{MPa}]\end{array}$ & $\begin{array}{c}\text { Anisotropy } \\
\text { factor } R\end{array}$ & $\begin{array}{c}\text { Biaxial } \\
\text { anisotropy factor } \\
R_{\mathrm{b}}\end{array}$ \\
\hline $0^{\circ}$ & 560 & & 0.77 & 0.75 \\
\cline { 1 - 2 } & $55^{\circ}$ & 550 & 1.01 & \\
\hline $90^{\circ}$ & 566 & & 1.12 & \\
\hline
\end{tabular}

Table 3. Mechanical properties of TWIP 940 steel sheet from Chung et al. (2011)

\begin{tabular}{ccccc}
\hline Orientation & $\begin{array}{c}\text { Yield stress } \\
{[\mathrm{MPa}]}\end{array}$ & $\begin{array}{c}\text { Biaxial yield } \\
\text { stress } \sigma_{\mathrm{b}}[\mathrm{MPa}]\end{array}$ & $\begin{array}{c}\text { Anisotropy } \\
\text { factor } R\end{array}$ & $\begin{array}{c}\text { Biaxial } \\
\text { anisotropy factor } \\
R_{\mathrm{b}}\end{array}$ \\
\hline $0^{\circ}$ & 457.2 & & 0.816 & \multirow{2}{*}{0.7} \\
\cline { 1 - 2 } & $45^{\circ}$ & 457.2 & 1.188 & \\
\hline $90^{\circ}$ & 481.7 & & 1.339 & \\
\hline
\end{tabular}


Table 4. Normalized flow stresses at different amounts of specific plastic work $w$ in uniaxial tension and hydraulic bulge tests from Xu and Barlat (2011)

\begin{tabular}{lcrrrr}
\hline Material & $w[\mathrm{MPa}]$ & \multicolumn{1}{c}{5} & \multicolumn{1}{c}{50} & 119 & 205 \\
\hline TWIP980 & $\sigma_{0} / \sigma_{0}$ & 1 & 1 & 1 & 1 \\
& $\sigma_{45} / \sigma_{0}$ & 0.99 & 0.981 & 0.978 & 0.98 \\
& $\sigma_{90} / \sigma_{0}$ & 1.009 & 0.987 & 0.98 & 0.983 \\
& $\sigma_{\mathrm{b}} / \sigma_{0}$ & 0.981 & 0.978 & 0.976 & 0.979 \\
\hline
\end{tabular}

Tables 5, 6, and 7 list the values of the eight anisotropy parameters for the Yld00-2d yield function calculated for different values of the exponent $a$. An efficient Newton-Raphson procedure was used to numerical identification of the yield function coefficients using experimental data involving three yield stresses $\left(\sigma_{0}, \sigma_{45}, \sigma_{90}\right)$ and three $\mathrm{R}$-values $\left(R_{0}, R_{45}, R_{90}\right)$, from uniaxial tension, the balanced biaxial yield stress $\left(\sigma_{\mathrm{b}}\right)$ and the corresponding biaxial Rvalue $\left(R_{\mathrm{b}}\right)$. More details can be found in the original paper of Barlat et al. (2003). The different exponents in the identification of the Yld000-2d coefficients are used with the purpose of analyzing the effect of the sharpness of the yield locus in equibiaxial stretching in the prediction of the FLD.

Table 5. Coefficients of the Yld00-2d yield function for TWIP4EU steel

\begin{tabular}{lrrrrrrrrr}
\hline Material & $a$ & $\alpha_{1}$ & $\alpha_{2}$ & $\alpha_{3}$ & $\alpha_{4}$ & $\alpha_{5}$ & $\alpha_{6}$ & $\alpha_{7}$ & $\alpha_{8}$ \\
\hline TWIP4EU & 6 & 1.007 & 0.951 & 1.0003 & 0.979 & 1.027 & 1.079 & 1.003 & 0.996 \\
\hline
\end{tabular}

Table 6. Coefficients of the Yld00-2d yield function for TWIP980 steel

\begin{tabular}{lccccccccc}
\hline Material & $a$ & $\alpha_{1}$ & $\alpha_{2}$ & $\alpha_{3}$ & $\alpha_{4}$ & $\alpha_{5}$ & $\alpha_{6}$ & $\alpha_{7}$ & $\alpha_{8}$ \\
\hline \multirow{2}{*}{ TWIP980 } & 8 & 0.965 & 1.021 & 1.018 & 0.988 & 1.025 & 1.06 & 1.012 & 0.998 \\
& 6 & 0.944 & 1.040 & 1.012 & 0.982 & 1.032 & 1.065 & 1.012 & 0.996 \\
& 5 & 0.916 & 1.066 & 1.017 & 0.976 & 1.037 & 1.062 & 1.013 & 0.994 \\
\hline
\end{tabular}

Table 7. Coefficients of the Yld00-2d yield function for TWIP940 steel

\begin{tabular}{lccccccccc}
\hline Material & $a$ & $\alpha_{1}$ & $\alpha_{2}$ & $\alpha_{3}$ & $\alpha_{4}$ & $\alpha_{5}$ & $\alpha_{6}$ & $\alpha_{7}$ & $\alpha_{8}$ \\
\hline \multirow{3}{*}{ TWIP940 } & 8 & 1.013 & 0.945 & 1.034 & 0.955 & 1.012 & 1.023 & 0.996 & 0.937 \\
& 6 & 0.992 & 0.969 & 1.036 & 0.947 & 1.017 & 1.027 & 1.001 & 0.926 \\
& 5 & 0.962 & 1.003 & 1.054 & 0.940 & 1.021 & 1.017 & 1.006 & 0.915 \\
\hline
\end{tabular}


Table 8 lists the coefficients of the Yld00-2d yield function for TWIP980 steel calculated for the flow stresses at different amounts of plastic work per unit volume $w$ presented in table 4, using the exponent coefficient $a$ of 6 .

Table 8. Coefficients of the Yld00-2d yield function for TWIP980 steel for the flow stresses at different amounts of plastic work per unit volume $w$

\begin{tabular}{ccccccccccc}
\hline Material & $w[M P a]$ & $a$ & $\alpha_{1}$ & $\alpha_{2}$ & $\alpha_{3}$ & $\alpha_{4}$ & $\alpha_{5}$ & $\alpha_{6}$ & $\alpha_{7}$ & $\alpha_{8}$ \\
\hline TWIP980 & 5 & 6 & 0.944 & 1.040 & 1.012 & 0.982 & 1.032 & 1.065 & 1.012 & 0.996 \\
& 50 & 6 & 0.912 & 1.092 & 0.989 & 0.991 & 1.036 & 1.076 & 1.020 & 1.014 \\
& 119 & 6 & 0.903 & 1.109 & 0.984 & 0.994 & 1.038 & 1.082 & 1.023 & 1.019 \\
& 205 & 6 & 0.906 & 1.102 & 0.982 & 0.992 & 1.037 & 1.073 & 1.021 & 1.018 \\
\hline
\end{tabular}

The dislocation density based model was identified for the TWIP980 by Kim et all (2013). All details concerning the identification of DD_model are presented in their original paper. The microstructural evolution of TWIP980 was characterized in detail by transmission electron microscopy (TEM) and electron back-scattering diffraction (EBSD). Table 9 contains the material parameters of the TWIP980 steel sheet involved in the hardening DD_model.

Table 9. Material parameters of the dislocation density based microstructural model from Kim et al.

(2013)

\begin{tabular}{cc}
\hline Parameters & TWIP980 \\
\hline$\sigma_{0}$ & $170 \mathrm{MPa}$ \\
\hline$M$ & 3.06 \\
\hline$G$ & $70.2 \mathrm{GPa}$ \\
\hline$b$ & $2.56 \times 10^{-10}(\mathrm{~m})$ \\
\hline$\tau_{\mathrm{c}}$ & $1(\operatorname{second})$ \\
\hline$W$ & $0.015(\mathrm{eV})$ \\
\hline$C_{0}$ & $2.26 \times 10^{27}\left(\mathrm{~m}^{-3}\right)$ \\
\hline$e$ & $50(\mathrm{~nm})$ \\
\hline $\mathrm{d}$ & $2.64(\mu \mathrm{m})$ \\
\hline
\end{tabular}


The material parameters of the Swift hardening law identified for each material are presented in table 10.

Table 10. Material parameters of the Swift hardening law

\begin{tabular}{ccc}
\hline Swift law & TWIP4EU/TWIP980 & TWIP940 \\
\hline$K[\mathrm{MPa}]$ & 2250 & 2300 \\
\hline$\varepsilon_{0}$ & 0.11 & 0.064 \\
\hline$n$ & 0.65 & 0.62 \\
\hline
\end{tabular}

The deformation of TWIP steel is achieved by dislocation motion and twinning. The TWIPeffect is believed to be due mainly to a dynamic Hall-Petch effect. As the formation of mechanical twins involves the creation of new crystal orientations, the twins progressively reduce the effective mean free path of dislocations and increase the flow stress, resulting in a high strain hardening behavior.

The twinning effect in the formability of TWIP steel is analyzed through the dislocation density based hardening model proposed by Kim et al. (2013). As deformation twinning occurred only in a subset of the grains, the grain population was subdivided into twinned grains and twin-free grains. 


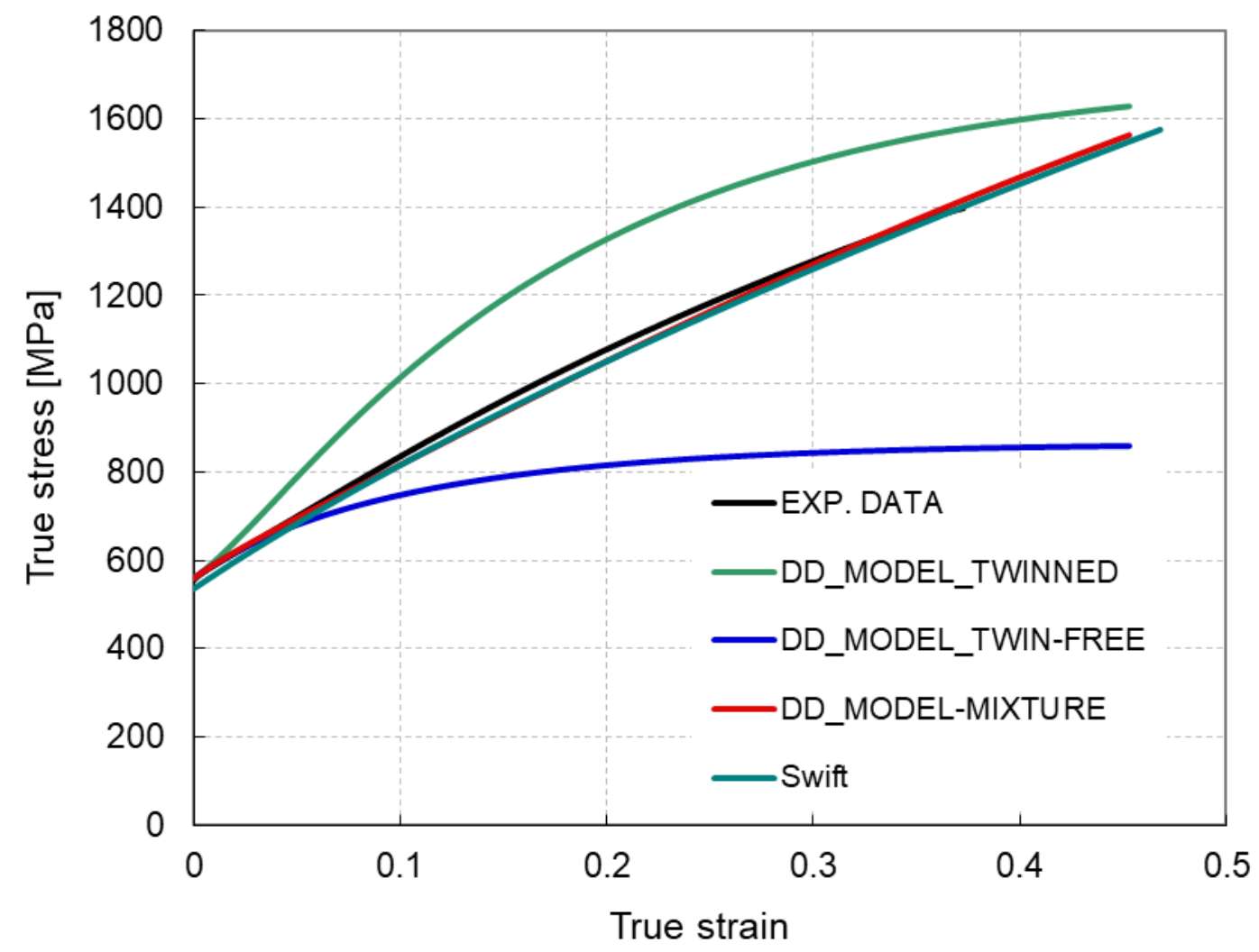

Fig. 2. Experimental and predicted stress-strain curves for the TWIP980 steel sheet specimen under uniaxial tension at $0^{\circ}$ from RD

In Fig. 2, the experimental true stress-true strain curve for TWIP980 steel sheet under uniaxial tension at $0^{\circ}$ from rolling direction is compared with the ones predicted by the Swift law and by the dislocation density based model for the twinned grains, twin-free grains and the mixture of twinned and twin-free grains. The flow stress of the twinned grains was calculated using Eq. (1) and Eq. (2), and includes the contribution of the DSA. As expected, the calculated flow stress is higher than the experimental flow stress. The flow stress of the twin-free grains calculated using Eq. (3) and Eq. (2), including also a contribution for the DSA effect, is lower than the experimental flow stress. The flow stress of the mixture of the twinned and twin-free grains calculated with Eq. 5 shows a good agreement with the experimental data. The dislocation density based hardening model and the Swift law are able to adequately fit the experimental data of the selected TWIP steel.

As previously mentioned, the high values of the strengths and uniform elongations of TWIP steel is due to the high rate of strain hardening associated with the deformation twinning 
phenomenon. A purpose of this work is to analyze the effect of these material properties in the formability of TWIP steel through the FLD concept.

As de Cooman et all. (2017) remarked, due to their low yield strength and large ductility, the failure mode of TWIP steel is usually ductile. The negative strain rate sensitivity makes diffuse necking strain small, and fast fracture is observed once necking is initiated. The main goal of the present study is to analyze the performance of the MK model for this type of material.

\subsection{Forming Limit Diagrams}

In the present study, the experimental FLDs determined by Butz et al. (2014) in the frame of the European Project TWIP4EU are used. The experimental forming limits were determined by the Nakazima tests using the cross section method and the time dependent linear best fit method. More information about these methods can be found in Butz et al. (2014). For the selected TWIP steel (acronym TWIP4EU steel) both evaluation methods lead to almost identical forming limits. It is well known that the lowest forming limit for a given material corresponds to the plane strain deformation state. The slight right shift of the experimental curve is due to the initial nonlinearity of the Nakazima experiments. But inevitable, all Nakazima measurements have this kind of shift to some extent. Hence, a small correction on the predicted FLD was applied to shift the curve to the right.

Fig. 3 shows the experimental and simulated forming limits for the TWIP4EU steel and TWIP980 steel under proportional loading, with the same selected constitutive equations namely, the Yld00-2d yield function and the Swift hardening law. According to Marciniak et al. (2002) a typical value of the MK inhomogeneity would be of the order of $\left(1-f_{0}\right)=0.001$. In this case, $\mathrm{f}_{0}$ should be around 0,999 , which is not appropriate for TWIP steel nor for a lot of materials. The homogeneity factor cannot be determined independently, but for small values of $\left(1-f_{0}\right)$, the curve will intersect the major strain axis at about the value of the strainhardening index $\mathrm{n}$, according the maximum tension condition applied from the second quadrant of the strain diagram (Marciniak et al., 2002). In case of the selected TWIP steel, $n$ $=0.65$, which means that the forming limit in plane strain should be around 0,65 , while in fact is around 0.35 . 


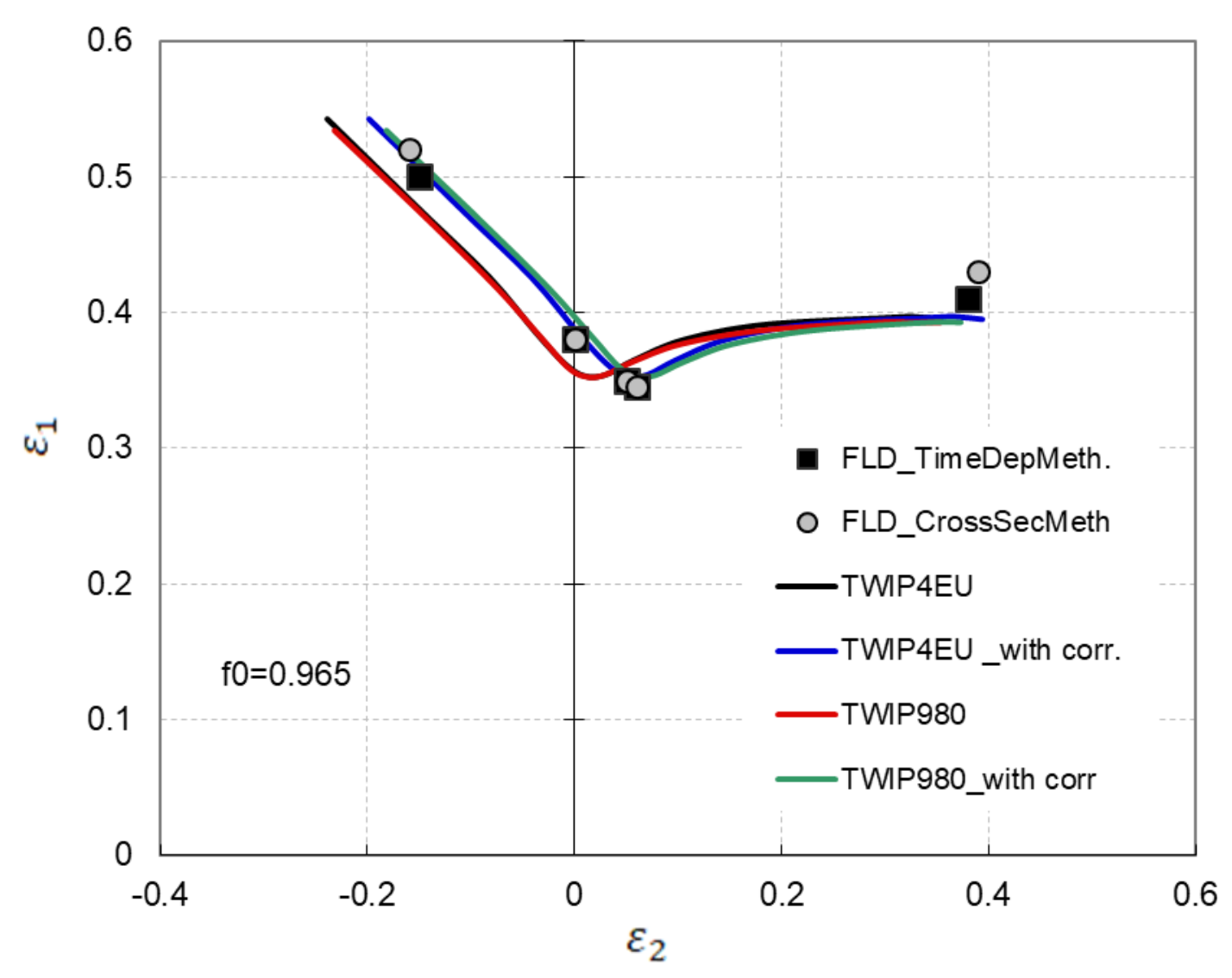

Fig. 3. Experimental and theoretical FLDs under linear strain paths for TWIP4EU steel and TWIP980 steel sheets, using Swift law and Yld00-2d yield function.

In order to achieve the best agreement with the experimental data, the initial value of the MK geometrical defect was set to 0.965 . It is observed a good correlation between theoretical and experimental forming limits for both of cases. Only a small under evaluation of the forming limits in the biaxial stretching region is noticed. Almost no differences are found between the predicted curves. These results confirm that the experimental FLD of TWIP4EU steel presented by Butz et al. (2014) can be used in our study having the TWIP980 steel selected as the representative material for TWIP steel, since, these materials are very similar. Using the MK theory, it is observed a rather correct prediction of the forming limits of TWIP steel but with an unusual high initial geometrical defect expressed by a small initial defect value of 0.965. The physical basis for the MK analysis was well presented in McCarron et al. (1988). In their study, imperfections in the form of grooves were introduced in samples used in equal biaxial stretching. It was found that no reductions in forming limit strain were obtained with shallow grooves for which the imperfection indices, defined as the thickness ratio of the groove to the nominal area, were greater than 0.990 and 0.992 for two different steels. Barlat et al. (1985), using an internal damage model associated to the MK model found that, in the 
absence of damage characterization, it seems reasonable to use a value in range of 0.9960.998 to quantitatively characterize the imperfection. He explained that the increasing defect is counterbalanced by two types of material hardening: the work-hardening and the "yield surface shape hardening" introduced by Lian et al. (1989), which is related to the yield surface shape effect. Nurcheshmeh and Green (2016) used the MK imperfection factor related to the surface roughness and the grain size following the empirical formulation of Stachowicz (1988). Based on these equations, $f_{0}$ values were calculated to be 0.995 and 0.997 for the AISI-1012 steel and the AA-2008-T4 alloy, respectively, in fact, values that are usually assumed for these materials. So, the question about the origin of such small value required in this study arises.

\subsubsection{Effect of the mechanical properties of the TWIP steel on the predicted forming limits}

\section{i) Effect of work-hardening coefficient on FLDs}

One of the most important characteristics of TWIP steel is the very high work-hardening coefficient, namely 0.65 for TWIP980. Thus, the relation between the strain hardening coefficient and the value of the initial geometrical MK defect is analyzed. For this purpose, several values between 0.25 and 0.7 were considered for the work hardening coefficient (n) in the Swift equation to simulate the FLD for TWIP980 using an initial geometrical value " $\mathrm{f}_{0}$ " of 0.99 , which appears reasonable for steel sheet according to the previous studies. The results are presented in fig. 4 . It is observed that a considerable increase of the forming limit strains is accompanied with the increase of the work hardening coefficient. With $\mathrm{f}_{0}=0.99$ and $\mathrm{n}=0.65$, the predicted forming limit strains for TWIP980 are over estimated. In order to achieve the best agreement with the experimental data in uniaxial tension, the initial value of the MK geometrical defect was individually selected for each case as presented in Table 11. Figure 5 shows the FLD of TWIP980 steel predicted using these values for $n$ and $f_{0}$. It is noticed that the relation between $\mathrm{n}$ and $\mathrm{f}_{0}$ is a decreasing linear function as Fig.6 shows. According to previous studies where the value of $f_{0}$ for steel sheet were between 0.99 and 0.992, it can be observed from Fig. 6 that " $n$ " must be smaller than 0.5 for f0 to be greater than 0.99 . This is, in fact, applicable to most steel sheets, which usually exhibit a " $n$ " value lower than 0.3. In conclusion, the small value of the initial MK geometrical defect is due to the high work-hardening coefficient of the TWIP steel. 


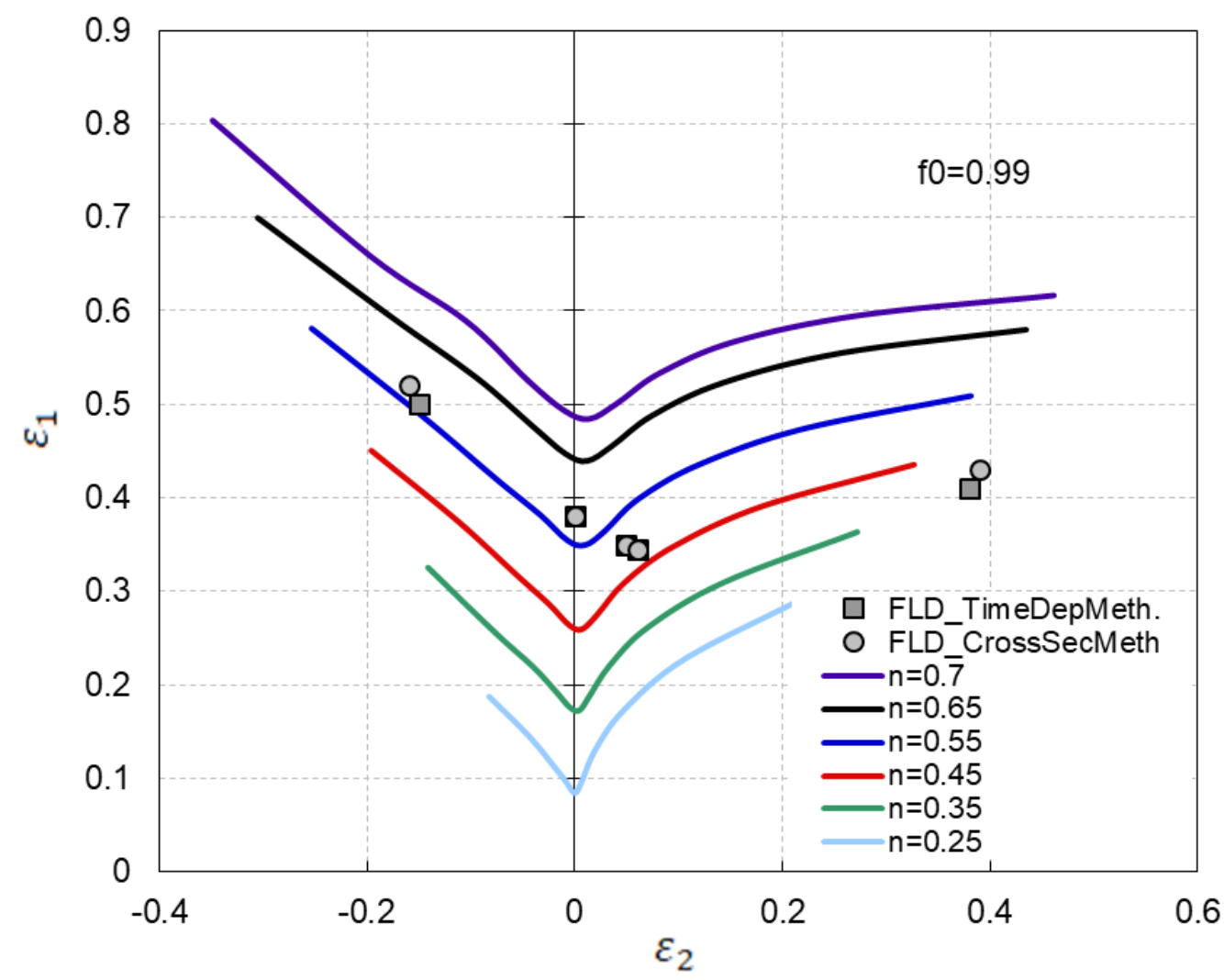

Fig. 4. The influence of work-hardening coefficient on FLD for TWIP980 steel

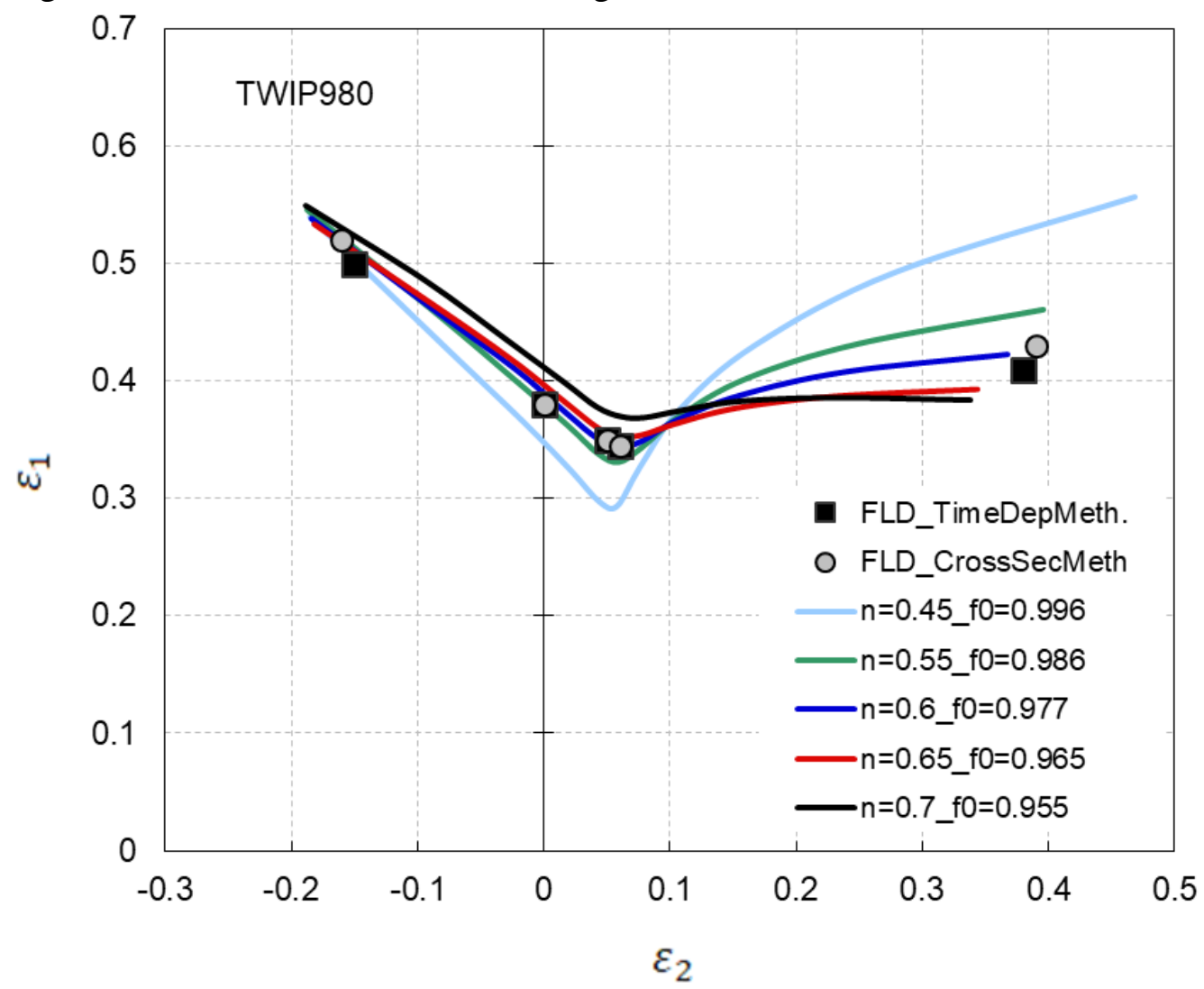

Fig. 5. The FLD for TWIP980 steel using several values of work-hardening coefficient and the corresponding initial value of the M-K geometrical defect 


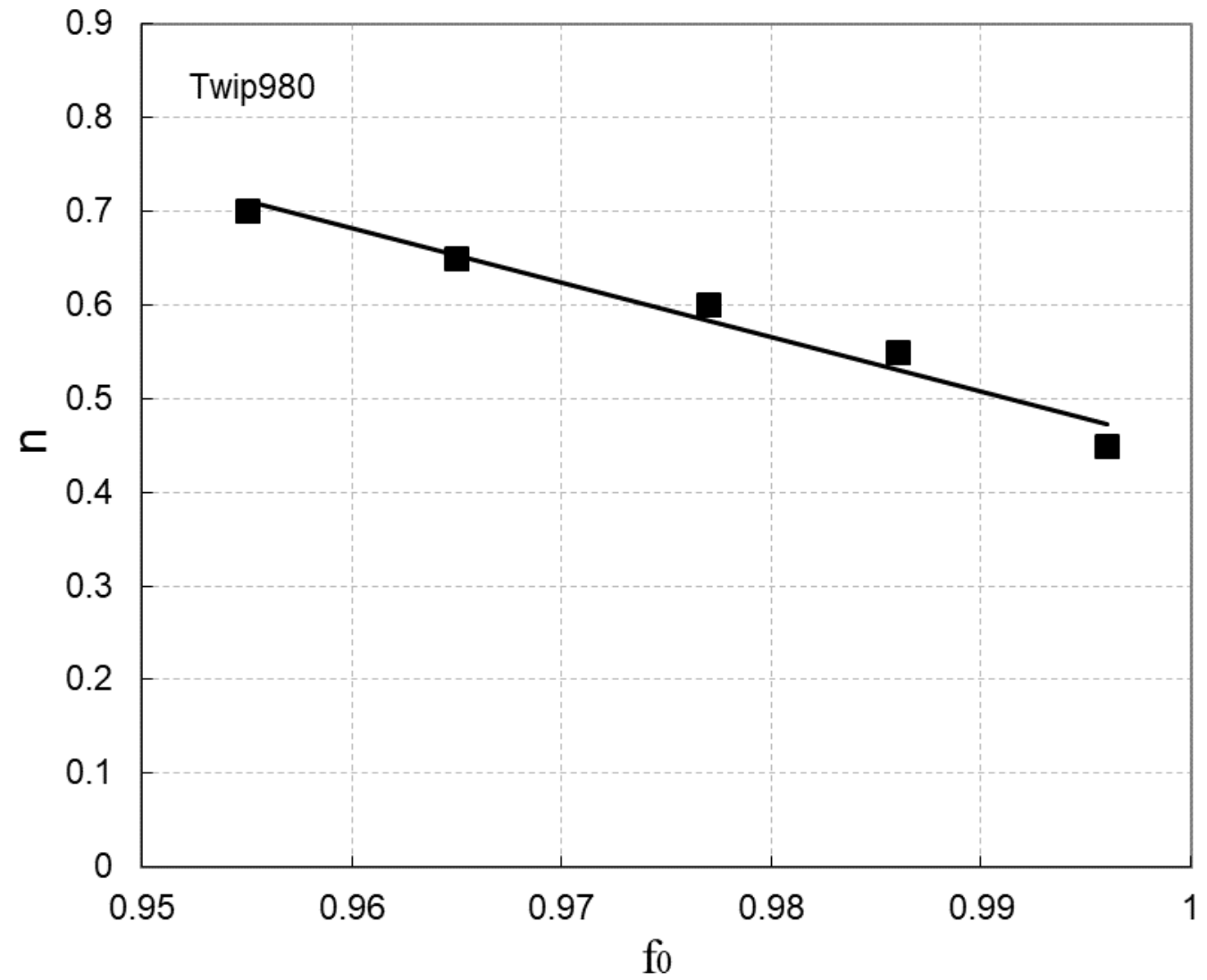

Fig. 6. The relationship between the work-hardening coefficient and the selected initial value of the M-K geometrical defect

Table 11. The initial geometrical value for different $\mathrm{n}$ for TWIP980 steel

\begin{tabular}{cccccc}
\hline $\mathrm{n}$ & 0.45 & 0.55 & 0.6 & 0.65 & 0.7 \\
\hline $\mathrm{f}_{0}$ & 0.996 & 0.986 & 0.977 & 0.965 & 0.955 \\
\hline
\end{tabular}




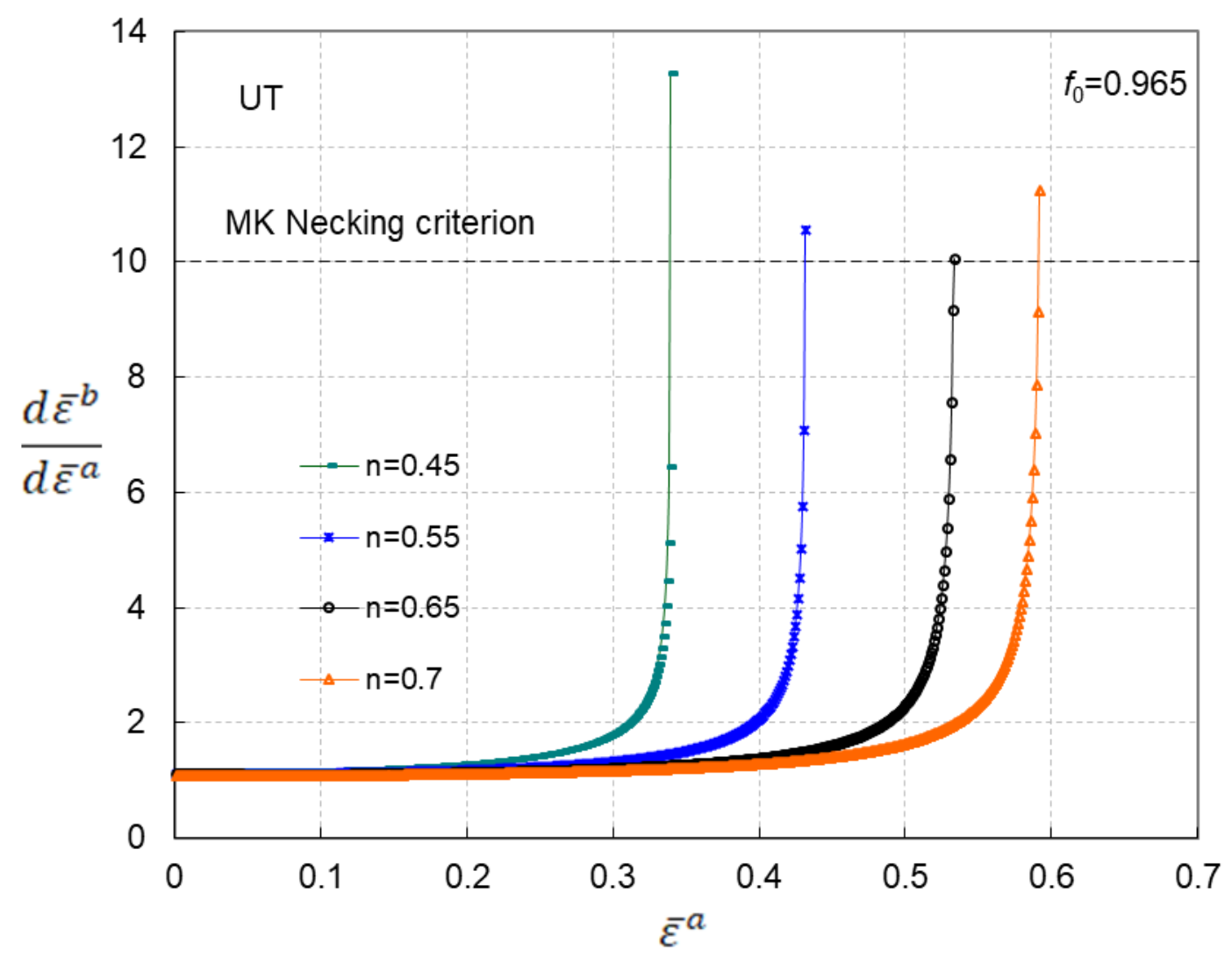

Fig.7 The effect of the strain hardening on the evolution of the MK necking criterion in uniaxial tension of TWIP980 steel

In order to understand these results, the effect of the strain hardening coefficient on the MK concept is studied, by observing the evolution of the MK necking criterion, the evolution of the MK geometrical defect and the evolution of the equivalent strain in the homogeneous and heterogeneous zones while varying its value. As expected, fig. 7 shows that the increase of the $\mathrm{n}$ value allows to a considerable delay in the achievement of the MK necking criterion, $\mathrm{a}$ fact, which explains the predicted forming limits results. Statistically, an increase of 0.05 or 0.25 in $n$ value corresponds to an increase of $5.8 \%$ and $25.3 \%$, on equivalent plastic strain, respectively. From fig. 8, by comparing the evolution of the MK necking criterion while the initial geometrical values are 0.992, the one usually assumed for steel sheets and 0.965, the one proper for the TWIP steel, it is observed that a decrease of $2.7 \%$ on the geometrical value allows a decrease of $19.2 \%$ on equivalent plastic strain. The effects of the work hardening coefficient and the initial geometrical value play a significant role on the attainment of the MK necking criterion. Fig. 9 depicted their influence on the evolution of the MK geometrical defect, considering several values of $n$ and two values for the initial 
geometrical defect, namely 0.992 and 0.965 as in the previous case. High values of $\mathrm{n}$ and $\mathrm{f}_{0}$ delay considerable the growth of the geometrical defect.

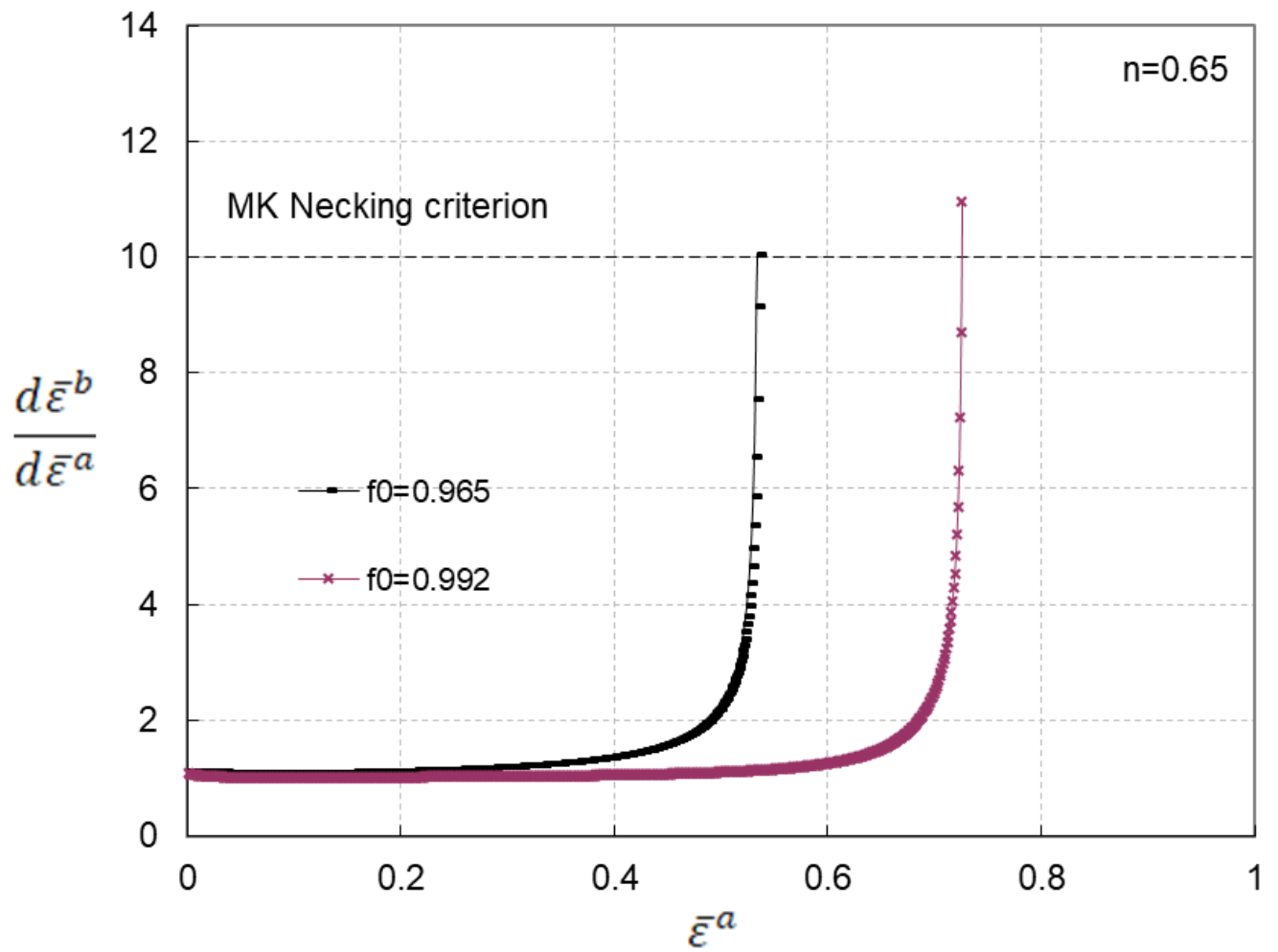

Fig. 8 The effect of the initial geometrical defect value on the evolution of the MK necking criterion in uniaxial tension of TWIP steel 


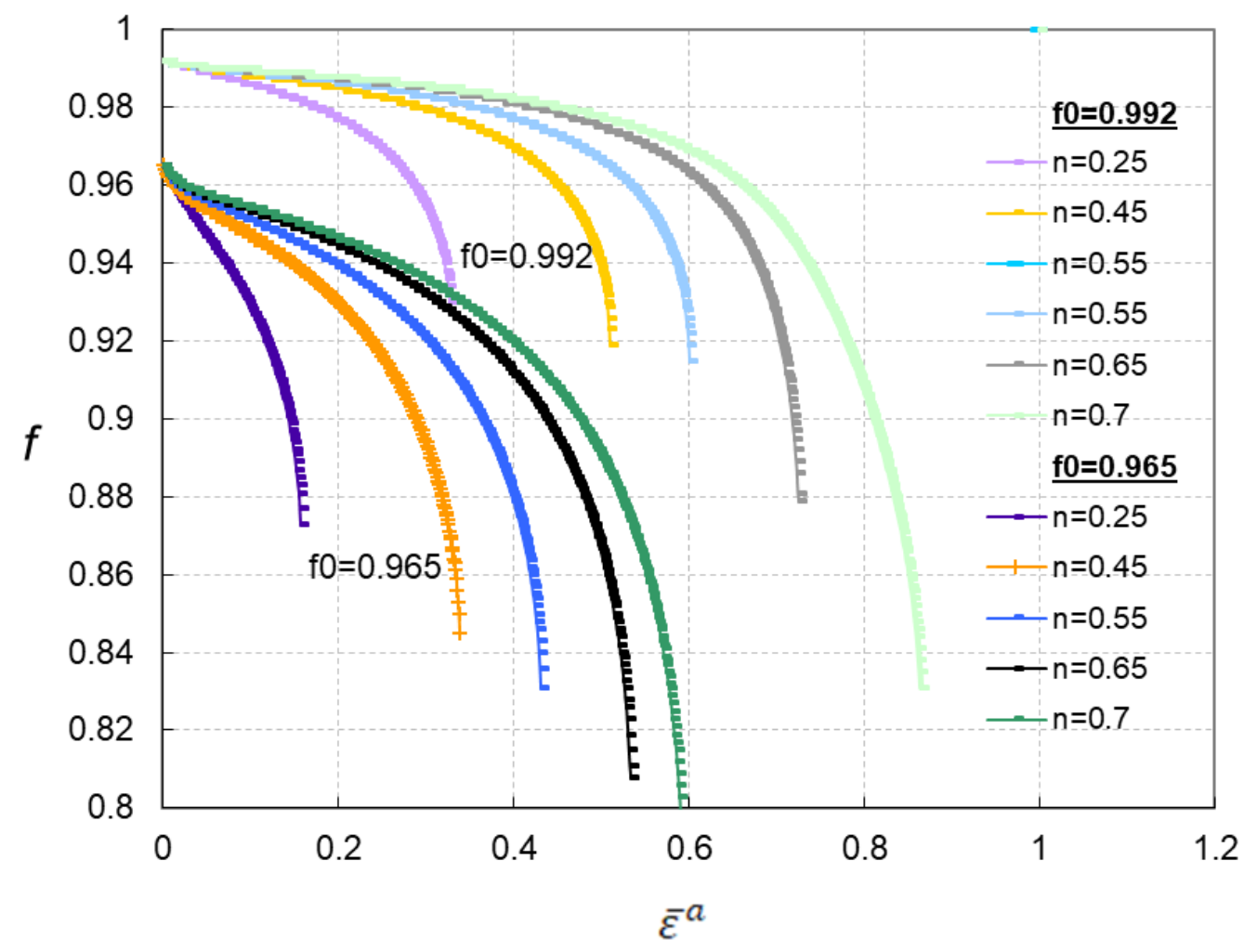

Fig. 9 The effect of the hardening coefficient and $f_{0}$ on the evolution of the MK geometrical value

\section{ii) Effect of strain rate sensitivity coefficient in FLDs}

Using Swift law accounting the strain rate sensitivity (Eq.12), the effect of the strain rate sensitivity coefficient on the occurrence of the plastic flow localization was studied. $\bar{\sigma}=K\left(\varepsilon_{0}+\bar{\varepsilon}\right)^{n} \dot{\varepsilon}^{m}$

The forming limits of TWIP 980 steel were predicted using Yld00-2d yield function and Swift law taking into account the strain rate sensitivity. The variation of the strain rate sensitivity coefficient was selected in the positive range, namely taking the values: $0,0.002$, 0.004, 0.006 and 0.01. It can be observed from fig. 10 that the forming limits decrease with the decrease of the strain rate sensitivity. TWIP 980 steel exhibits a negative strain rate sensitivity coefficient, as Bintu et. al (2015) showed, but it is approximated in our study with 0 since the effect of negative $m$ cannot be captured by the MK theory. Theoretically, if supposing that the negative strain rate could be taken into account, the initial value of the MK geometrical defect should be slightly greater than 0.965 , to recover the decrease of forming limits due to the decrease of the strain rate sensitivity coefficient. 


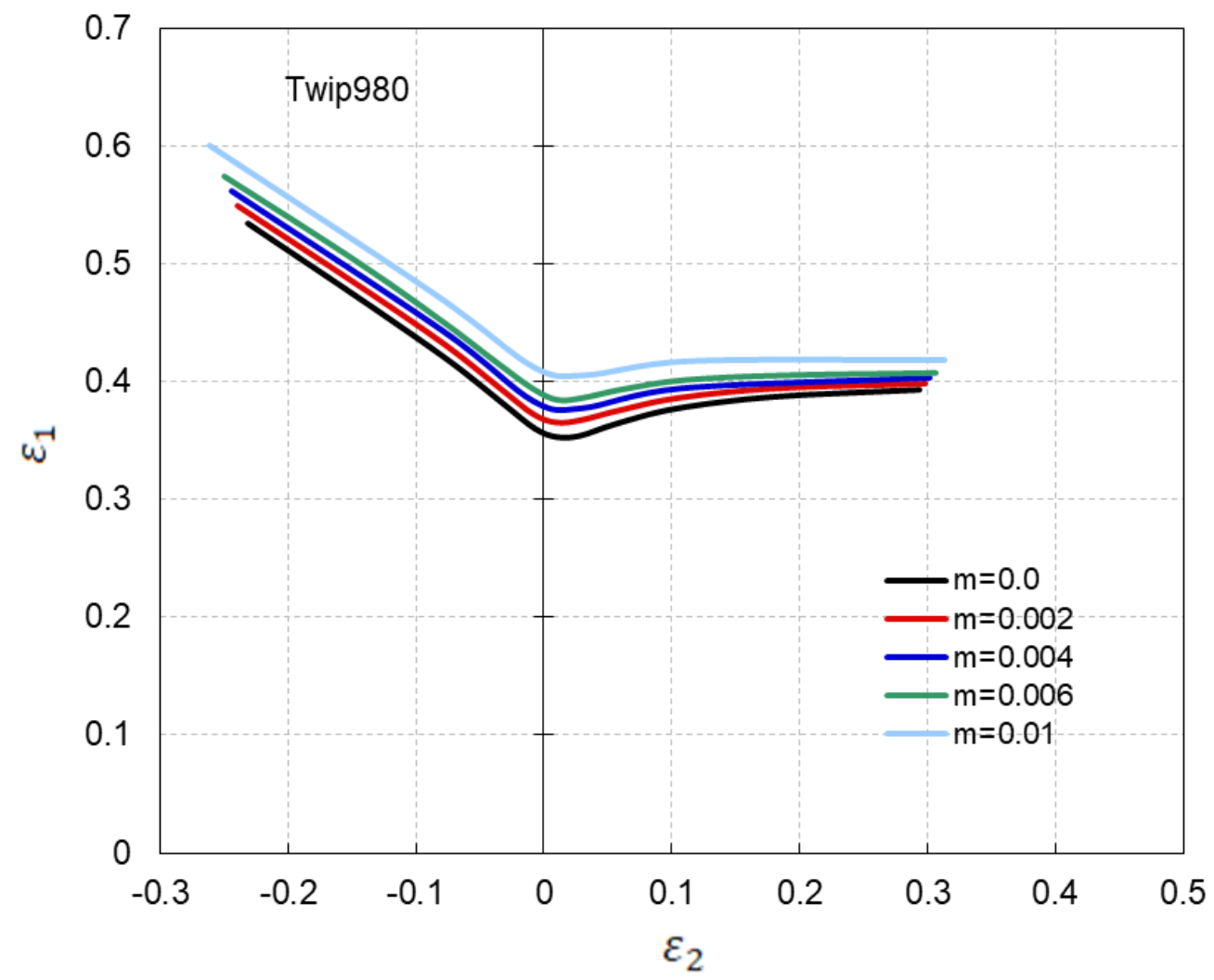

Fig.10 The influence of the strain rate sensitivity coefficient in FLDs of TWIP980 steel

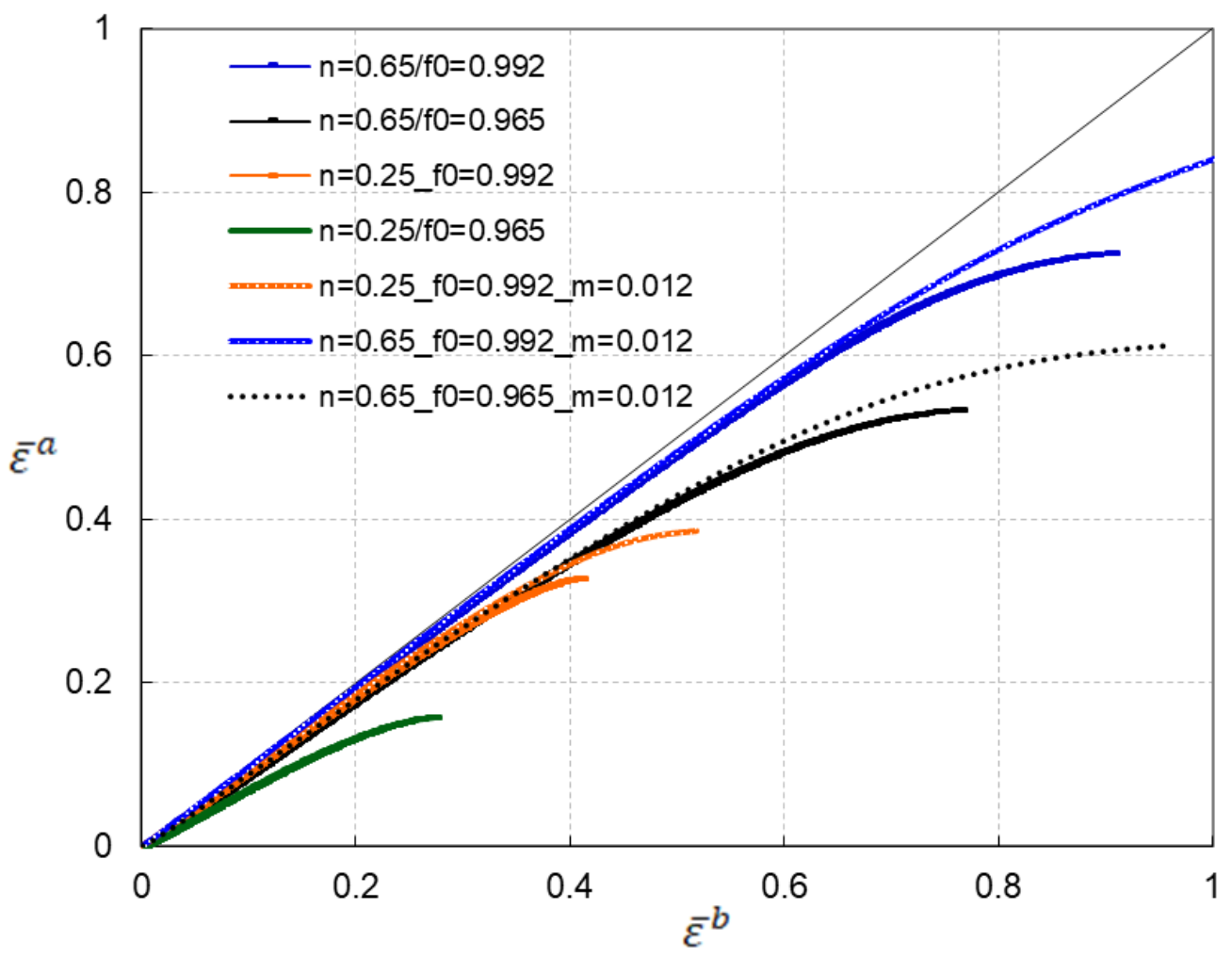

Fig. 11 The evolution of the equivalent plastic strain in the homogeneous zone versus the heterogeneous zone of MK approach 
The effect of the work hardening coefficient, strain rate sensitivity and initial geometrical value on the evolution of equivalent plastic strain in the homogeneous zone versus the heterogeneous zone of the MK approach is presented in Fig. 11.

Two values of each selected parameter are considered in this study, namely the ones typical for an usual steel as $n=0.25, f_{0}=0.992$ and the ones of the TWIP steel, like $n=0.65$ and $\mathrm{f}_{0}=0.965$ with $\mathrm{m}=0.0$ and $\mathrm{m}=0.012$.

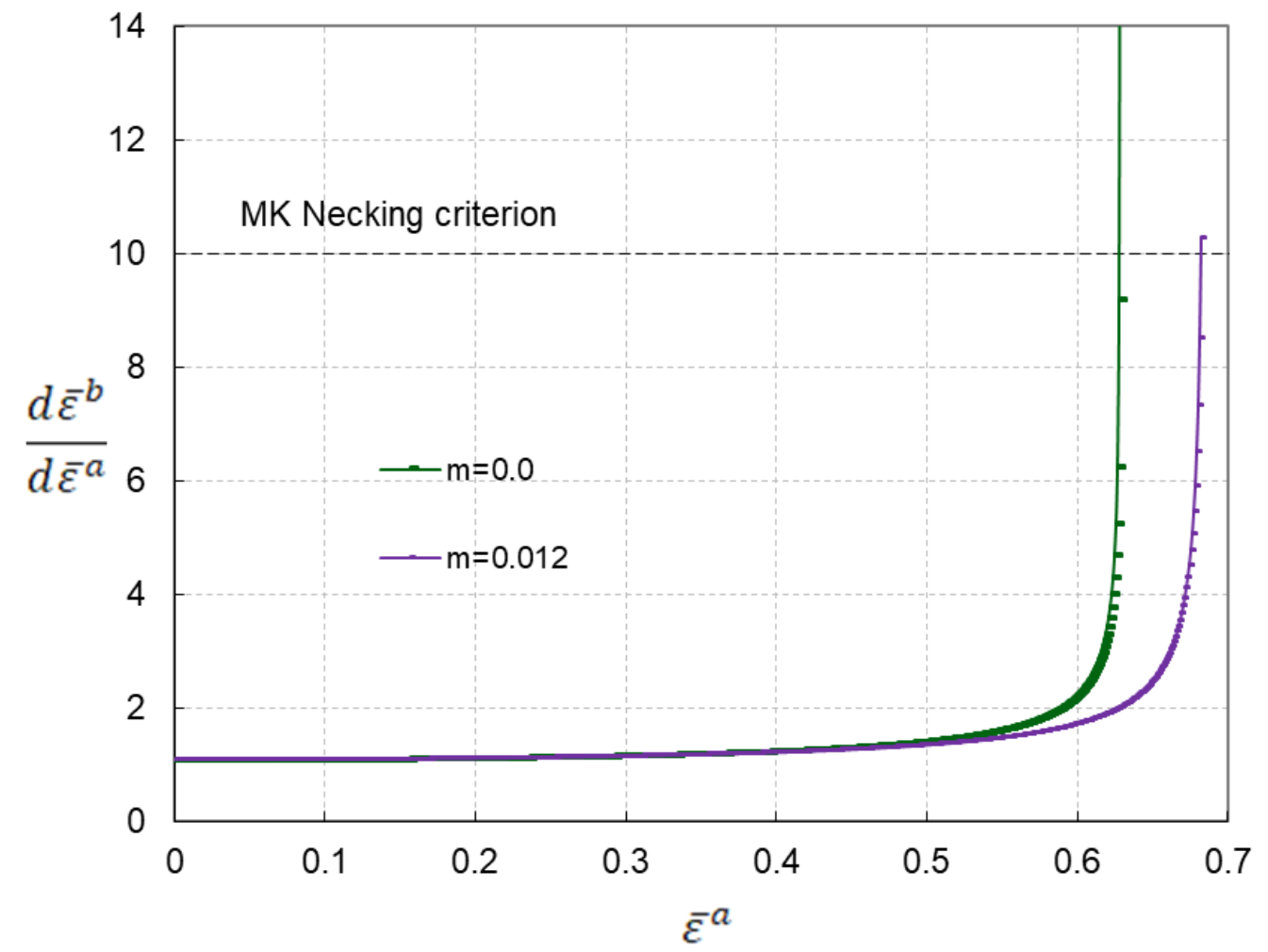

Fig. 12 The effect of the strain rate sensitivity coefficient on the evolution of the MK necking criterion 


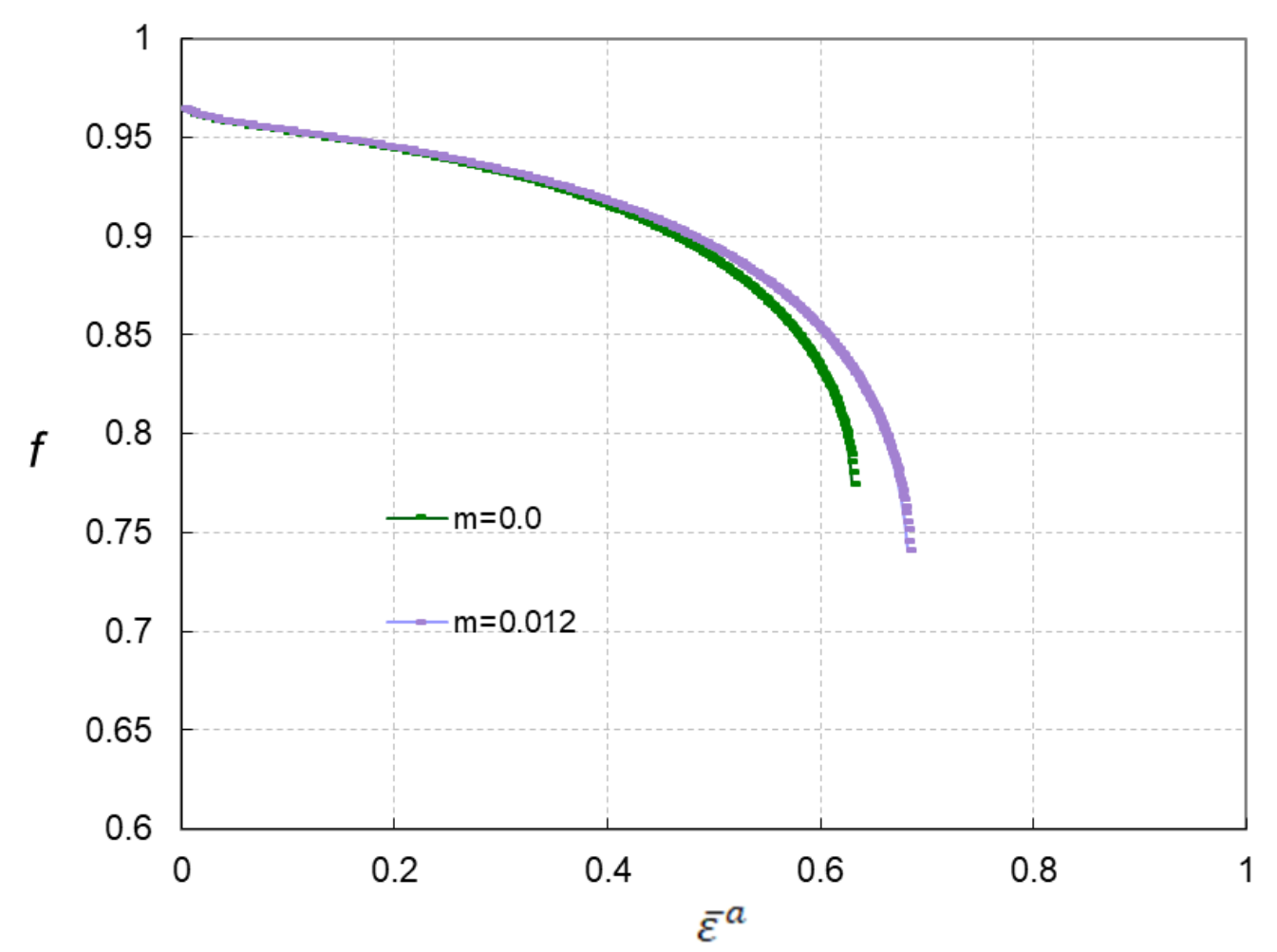

Fig. 13 The effect of the strain rate sensitivity coefficient on the evolution of the MK geometrical value

All selected parameters affected in a well-defined manner the faster increase of the plastic strain in the groove, which in fact is the basic principle of the MK theory. For TWIP steel the most pronounced effect appears to be the effect of work hardening coefficient.

An inspection of Figs. 12 and 13 indicates that the strain rate sensitivity delays the growth of the neck, which allows higher forming limits. From the TWIP steel point of view, the negative strain rate sensitivity should accelerate the growth of the neck and faster achievement of the MK necking criterion allowing to smaller predicted forming limits.

\section{iii) The effect of the anisotropy factors in FLD}

In the following, the influence of the anisotropy factors of the TWIP steels on the predicted FLD is presented. A particular property of the TWIP steel is the R-value in the rolling direction less than 1, an unusual fact for a traditional steel sheet. Varying the value of R0 between $0.6,0.77,1.0$ and 1.2 while keeping constant all another parameters of TWIP steel, the FLDs were predicted. 


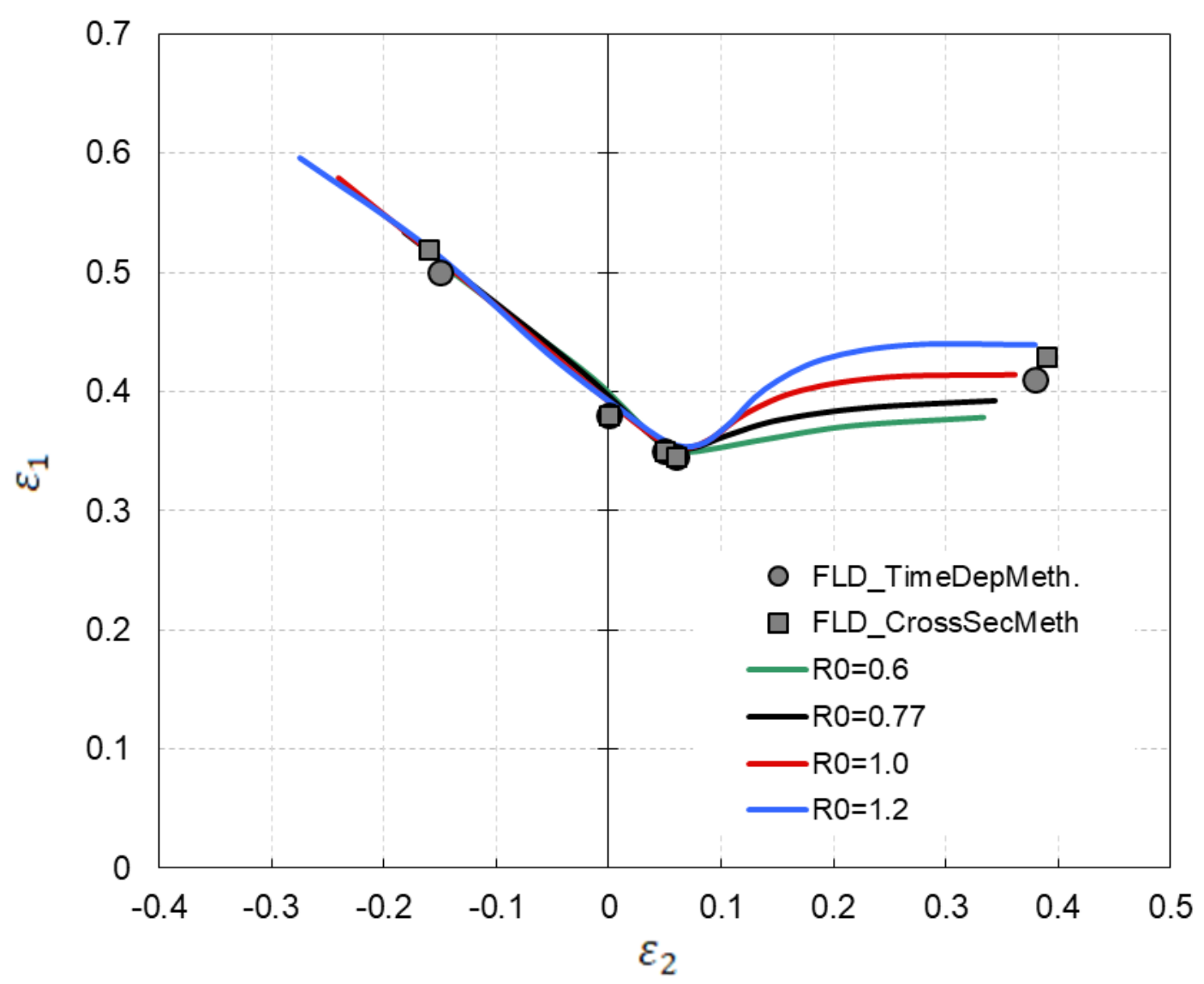

Fig.14 The influence of R0 in FLDs of TWIP980 steel

As fig. 14 shows, the $\mathrm{R}_{0}$ value has no effect on the left side of the FLD while the forming limits of the right side are significantly increased with the increase of the $R_{0}$ value. Specifically, an increase of $\mathrm{R}_{0}$ from 0.77 to 1.2 allows to an increase of $4.6 \%$ of the biaxial stretching forming limit. Therefore, it is possible to improve the formability in the biaxial stretching zone by augmenting the $\mathrm{R}_{0}$ value. The anisotropy parameter at $45^{\circ}$ from the rolling direction $\left(\mathrm{R}_{45}\right)$ has no effect on the predicted forming limits. The influence of the anisotropy factor at $90^{\circ}$ from rolling direction $\left(\mathrm{R}_{90}\right)$ has been studied by assuming different values of 0.8 , 1.12, 2.0 and 2.5 while keeping constant the other parameters. The simulated FLDs presented in fig. 15 show no effect of $\mathrm{R}_{90}$ in the left side of the diagram. In the meantime, in the right hand side of the FLD, a slight decrease of the forming limits occurs with the increase of the $\mathrm{R}_{90}$ value for low minor strains. However, an inversion of this effect appears for larger minor strains. In particular, a change of $\mathrm{R}_{90}$ from 1.12 to 2.5 leads to a biaxial stretching forming limit increase by $2.6 \%$. 


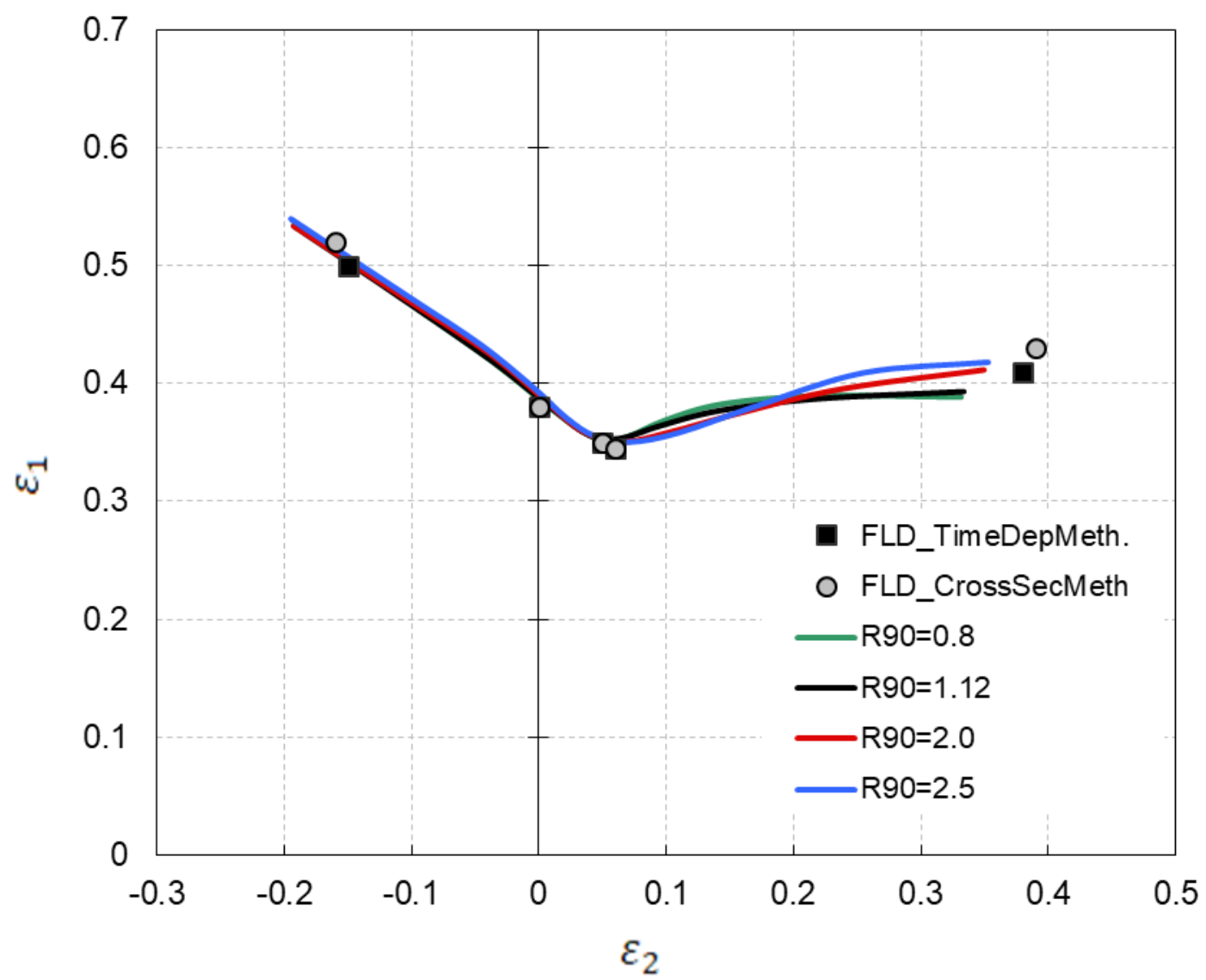

Fig.15 The influence of R90 in FLDs of TWIP980 steel

The balanced biaxial stretching $R$ value $\left(R_{b}\right)$ is varying between 0.65 and 1 . The simulated FLDs are presented in fig.16. No effect of the $R_{b}$ in the left side of the diagram is found. In the right side, the predicted forming limits decrease with the increase of $R_{b}$ value. Specifically, increasing $\mathrm{R}_{\mathrm{b}}$ from 0.7 to 1.0 , the biaxial stretching forming limit decreases by $1 \%$. 


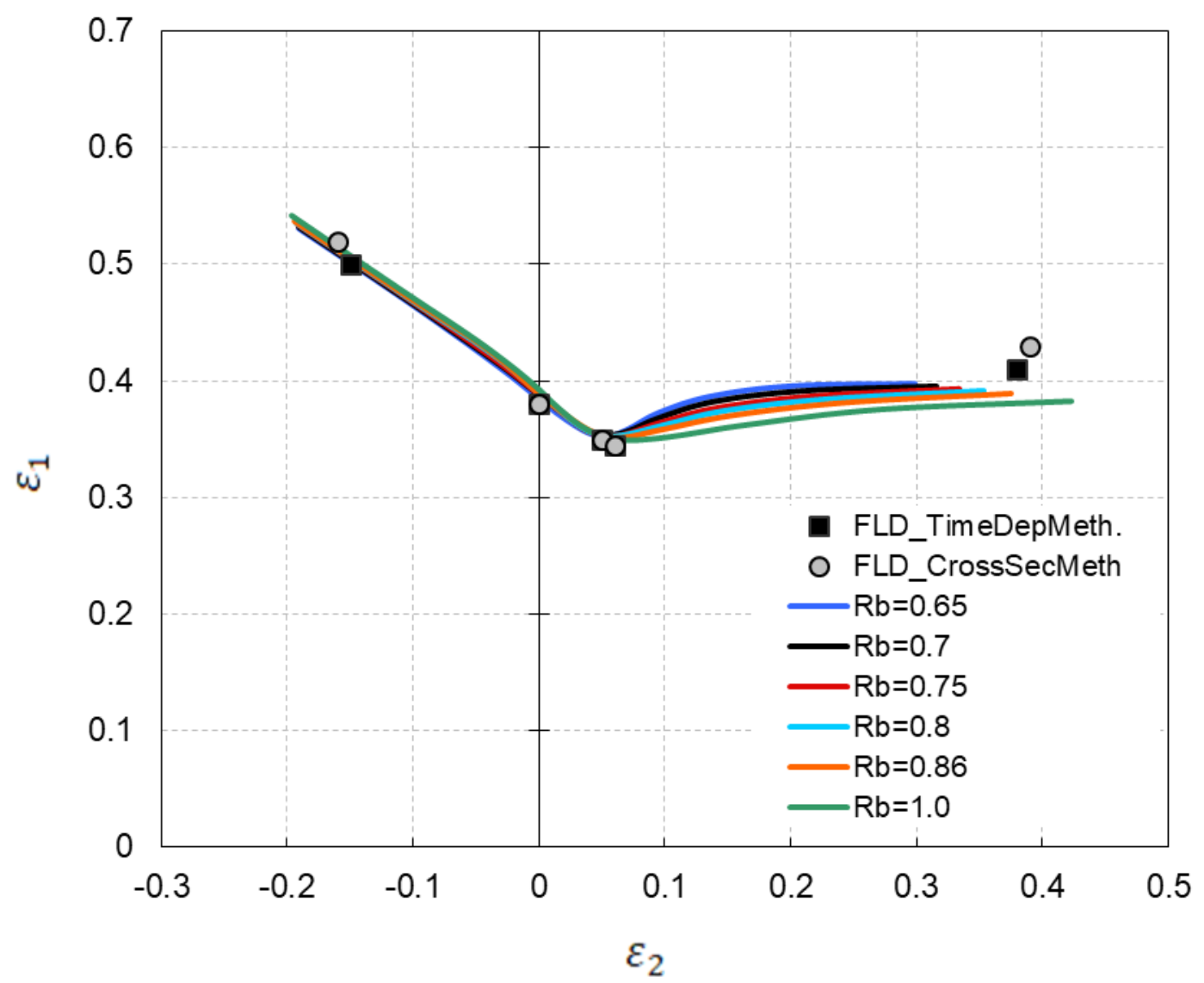

Fig.16 The influence of Rb in FLDs of TWIP980 steel

In conclusion, the anisotropy factors of the TWIP steel influence the predicted forming limits in the right side of the FLD, excluding $\mathrm{R}_{45}$ that has no influence. The most influent anisotropy factor is $\mathrm{R}_{0}$ but this achievement could be a result of the fact that the studied FLD is at $0^{\circ}$ from the rolling direction. The effect of the anisotropy factors on the FLDs is explained by their effect on the yield locus shape.

\section{iv) The influence of sharpness of the yield surface on FLDs}

The experimental yield points and the predicted plane stress yield surfaces for TWIP980 steel sheet are presented in Fig. 17. The balanced biaxial yield stress used as input in the identification of the coefficients of the Yld00-2d yield function ensures a great accuracy in the reproducibility of yield surface on the critical region of biaxial stretching. Through the exponent "a" of the yield function, the sharpness of the yield locus in equibiaxial stretching can be controlled, a fact that is very important in FLD predictions. The increase of the parameter "a" allows to an increase of the sharpness of the yield locus in equibiaxial stretching. Although for materials with face-centered cubic crystal structure FCC, like TWIP 
steels, an exponent of $\mathrm{a}=8$ is recommended, $\mathrm{Xu}$ et al.(2012) found that Yld00-2d with $\mathrm{a}=6$ leads to a better prediction of the experimental data.

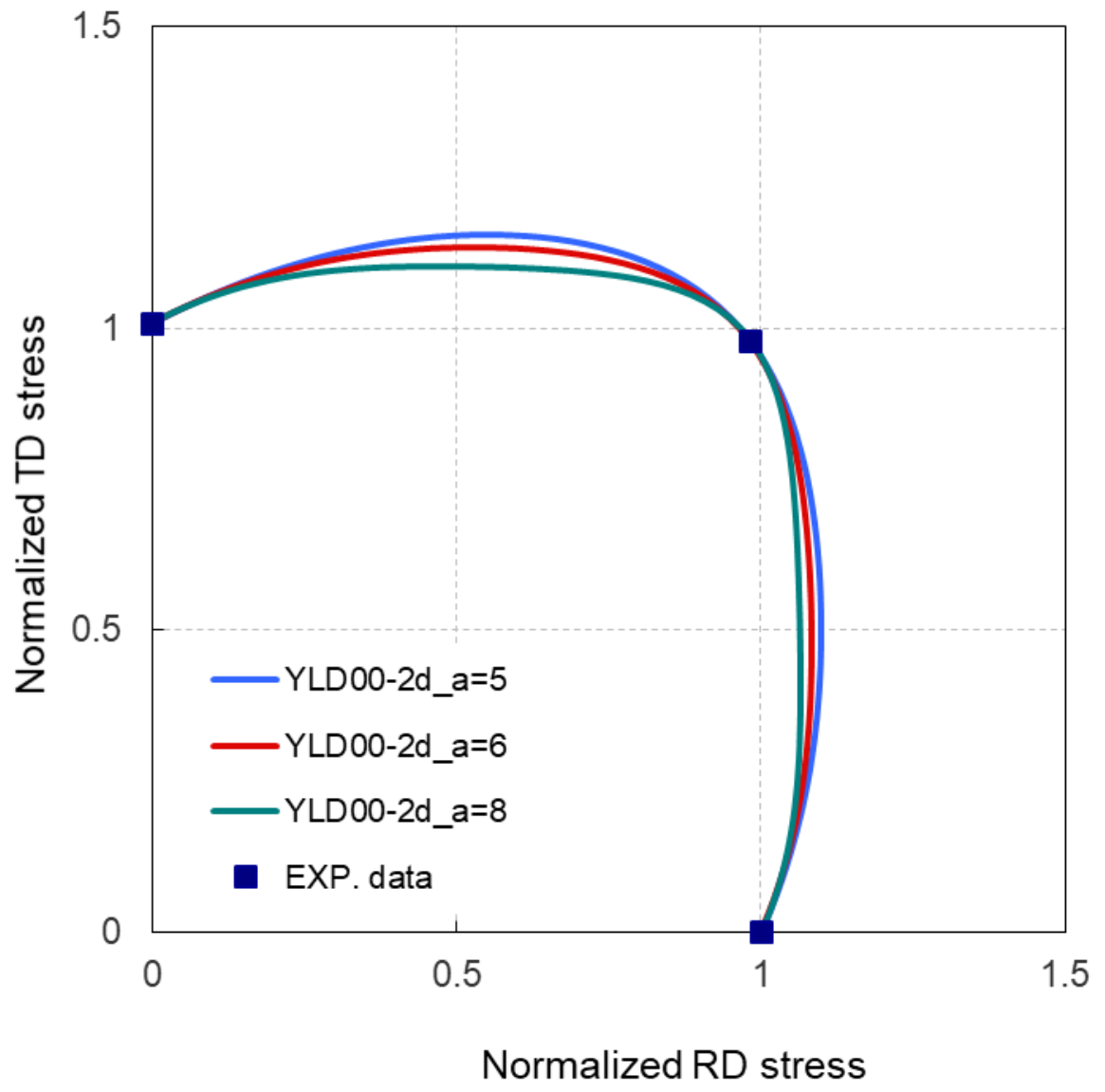

Fig. 17 Experimental and predicted Yield Surface of Twip980 Steel

Observing from Fig. 3 the under estimation of the forming limits in the biaxial stretching and taking into account the relationship between the exponent "a" and the yield locus curvature, a value of $a=5$ was selected for the simulation, in order to reduce the sharpness of the yield surface, factor promoting larger limit strains. Fig. 18 shows the Forming limit Diagrams of TWIP980 steel simulated with different values of "a" namely 5,6 and 8. A significant improvement of the accuracy of the predicted FLD of TWIP980 steel was achieved using $\mathrm{a}=5$. If the $\mathrm{f}_{0}$ value is slightly modified to 0.963 the predicted FLD reproduces almost perfectly the experimental data. These results can be tentatively attributed to twinning that appears during the deformation of the TWIP steels, which might influence the sharpness of the yield locus (Xu et al, 2012), by decreasing its curvature.

The ability of the yield function to reproduce the sharpness of the yield surface in the biaxial 
stretching region is fundamental for the prediction of the FLDs. A very small difference in the sharpness of the yield surface in the biaxial range, as between $a=5$ and $a=6$ in Fig. 18, has a significant impact in the predicted forming limits in the biaxial stretching.

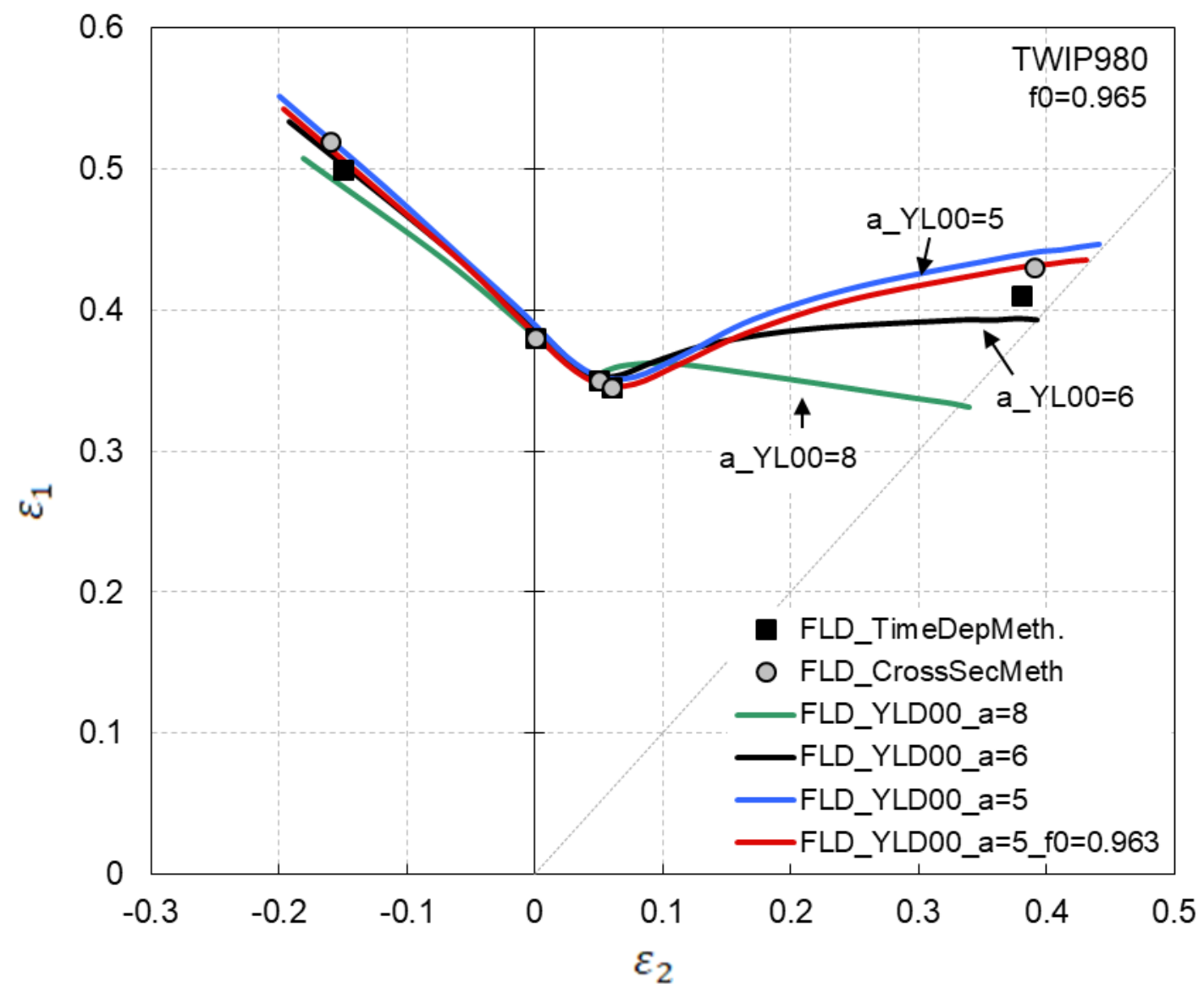

Fig. 18 The influence of sharpness of the yield surface on FLDs of TWIP980 steel predicted with Yld00-2d using different values of parameter "a"

Lian et al (2018) found that the evolution of anisotropic parameters during deformation is of importance in predicting the forming limit curve of a ferritic steel sheet. Bandyopadhyay et al. (2019) found an increase on the accuracy of the prediction of formability for two ferritic stainless steel sheets taking into account in the MK model the evolutionary shape of nonquadratic anisotropic yield function Yld2000-2d described at different effective plastic strain levels.

The influence of the evolution of the yield surface on the FLDs of TWIP980 steel predicted with Yld00-2d with the anisotropic coefficients identified using the flow stresses at different amounts of plastic work per unit volume (acronym w), namely 5, 50, 119 and $205 \mathrm{MPa}$ is presented in Fig. 19. It was observed no effect of the yield surface evolution in the FLD 
prediction of TWIP steel. These results are based on the fact that for this TWIP steel the work hardening is almost isotropic and the yield surface shape almost does not evolve during the deformation, as Xu and Barlat (2011) and Xu et al. (2013) found. Observing the table 4, the yield surface at the specific plastic work of $\mathrm{w}=5 \mathrm{MPa}$ could be valid for the whole deformation process up to fracture, as it was in fact considered in this study. In addition, it can be observed that the ratio of the balanced biaxial flow stress by the uniaxial tension flow stress at $0^{\circ}$ from the RD as a function of the plastic work is almost constant, no existing a decrease of it with the increase of the equivalent strain as in the study of Bandyopadhyay et al. (2019). This is obviously reflected in the predicted forming limits.

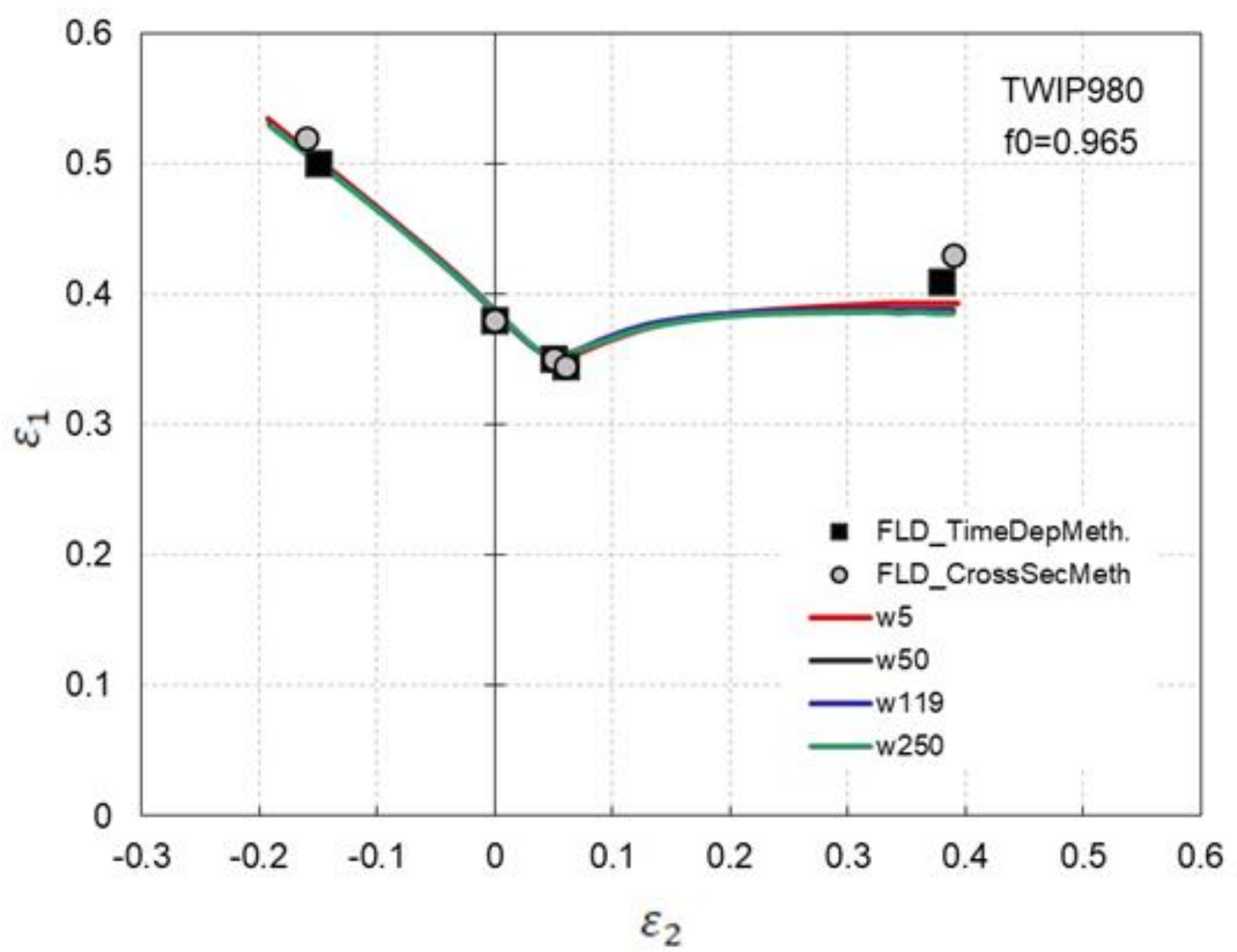

Fig. 19 The influence of the evolution of the yield surface on FLDs of TWIP980 steel predicted with Yld00-2d with anisotropic coefficients identified using flow stresses at different amounts of plastic work (acronym w) 


\subsubsection{Prediction of the FLDs of TWIP940 steel}

The present analysis is extended to the TWIP940 steel investigated by Chung et al. (2011) in their study. These authors evaluated experimentally and numerically the macroscopic performance of automotive TWIP steels sheets to assess formability by applying Dorn's and Swift's theoretical predictions for diffuse necking as well as Hill (1952) and MK approaches for localized necking. They applied Hill's bifurcation theory to predict the left side of the FLD and the MK theory to predict the right side. The initial geometrical value of the MK theory was obtained using as reference the forming limit predicted by Hill's theory under the plane strain condition. These authors found that TWIP940 failed much earlier than the predicted onset of diffuse necking for all deformation modes, suggesting that the failure of the TWIP940 sheet occurred by fracture without strain localization. Actually, TWIP940 has a major drawback in formability because it fails in the uniform deformation range without further deformation in the post-uniform range unlike typical ductile steel sheets. Using the material parameters identified by Chung et al. (2011) and the same constitutive equations, namely, Yld00-2d and Swift equation, the FLDs of TWIP940 steel were simulated with the FLD code using the extended MK model. The theoretical FLDs were compared with the experimental forming limits presented by Chung et al. (2011) in Fig.20. In the simulations, a coefficient of $a=8$ was considered as in the original study of Chung et al. Two values were selected for the initial MK geometrical defect, namely 0.97 and 0.992. The FLD predicted using $\mathrm{f}_{0}=0.97$ reproduces rather well the left side of the diagram while considerably underestimates the right side. With $\mathrm{f}_{0}=0.992$ the theoretical forming limits are in a good agreement with the experiments in the right side of the diagram, especially for the biaxial stretching forming limit, but considerably overestimates the forming limits in the left side. 


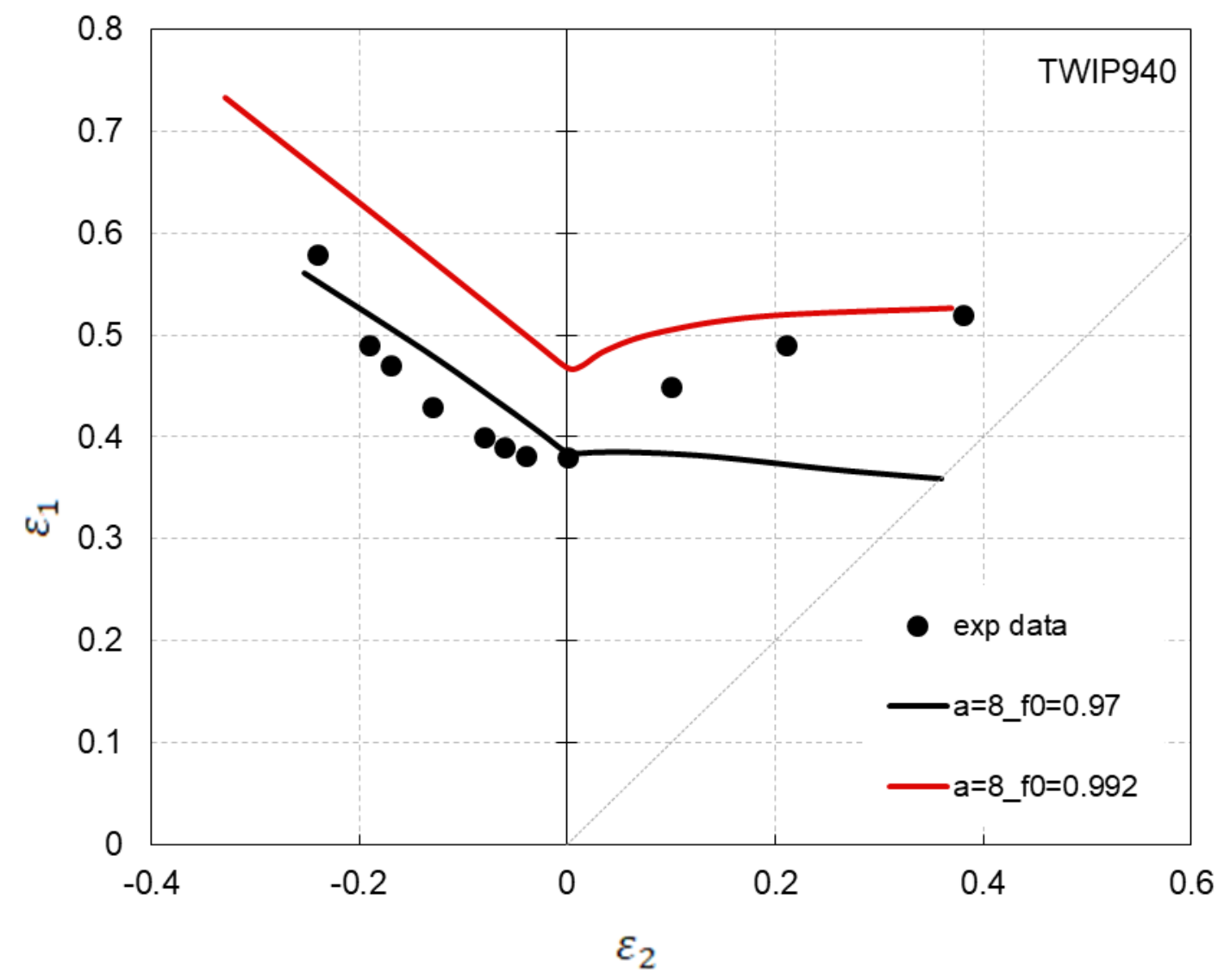

Fig.20 Experimental and theoretical FLDs under linear strain paths for TWIP940 steel, using Swift law and Yld00-2d yield function.

To take the analysis further, fig. 21 shows the FLDs of TWIP940 steel simulated considering the effect of the sharpness of the yield locus by applying several values of a, specifically 8,6 and 5. It is observed a considerable increase of the accuracy of the simulated FLD with $a=5$, as in the case of the TWIP980. As previously mentioned, the balanced biaxial yield stress $\left(\sigma_{b}\right)$ plays an important role in the accuracy of the predicted yield surface on the biaxial stretching region. Fig. 22 shows the effect of the balanced biaxial yield stress on the FLDs of TWIP940 by considering different values of the balanced biaxial yield stress normalized by the uniaxial yield stress at $0^{\circ}$ from rolling direction (acronym $\operatorname{sig}_{\mathrm{b}} / \mathrm{sig}_{0}$ ) for the identification of the Yld00-2d coefficients, namely 1.0, 0.98 and 0.96. It is worth noting that Chung et al. used a normalized $\sigma_{b}$ equals to 1.0 , probably as an assumption when the experimental value of $\sigma_{b}$ is not available. The predicted forming limits in the biaxial range increase with the decrease of the normalized $\sigma_{b}$ while no effect are observed in the left side of the FLD. Using a normalized $\sigma_{\mathrm{b}}$ equals to 0.98 , the same value identified for TWIP980, the predicted FLD is 
in a very good agreement with the experimental forming limits especially in uniaxial tension, plane strain and biaxial stretching.

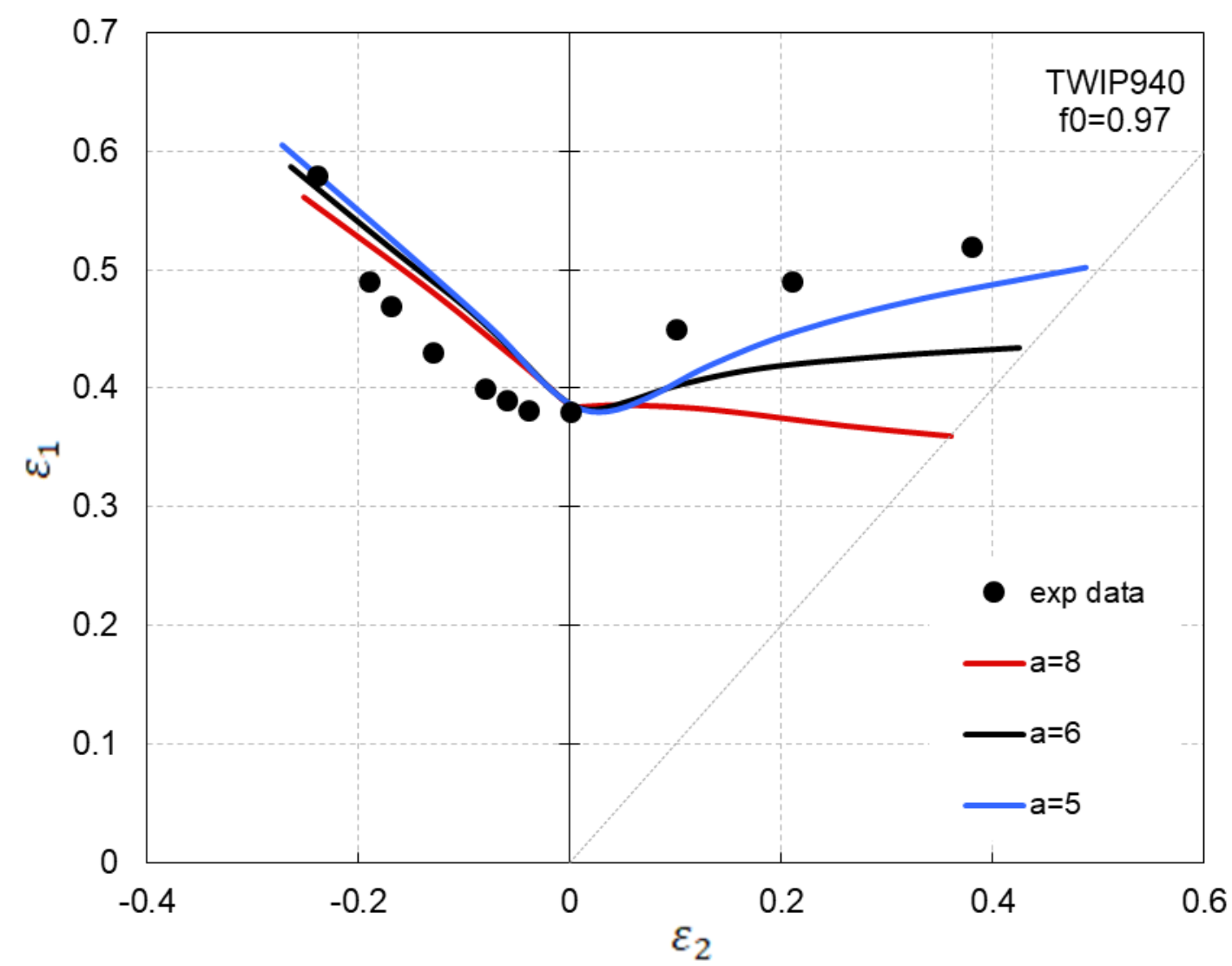

Fig. 21 The effect of sharpness of the yield surface on FLDs of TWIP940 steel predicted with Yld00-2d using different values of parameter "a" and $f_{0}$ of 0.97

In conclusion, the MK model through the FLDcode is able to predict the FLD of TWIP940 steel with a good accuracy while using an initial MK geometrical value $\mathrm{f}_{0}$ of 0.97 , the parameter "a" of Yld00-2d of 5 and the normalized biaxial yield stress of 0.98. It was achieved a considerable improvement of the prediction of the FLD of the TWIP940 steel by comparing with the results presented by Chung et al. (2011), but using an unusual large initial MK geometrical defect as it was found for the previous studied cases of TWIP and TWIP980 steels. 


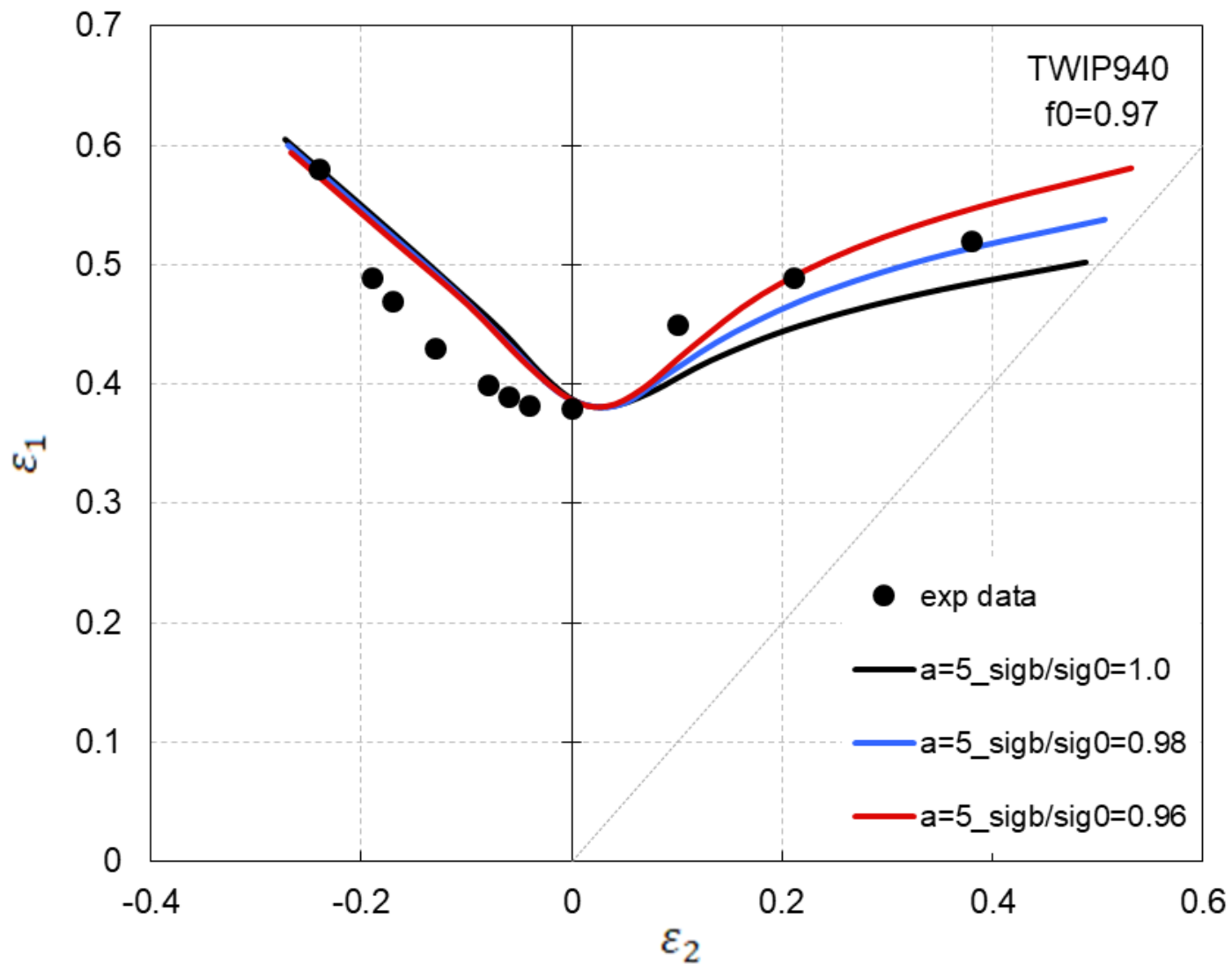

Fig. 22. The effect of the normalized balanced biaxial yield stress on FLDs of TWIP940 steel predicted with Yld00-2d

\subsubsection{Predicting FLD using the dislocation density based microstructural model}

The forming limits of TWIP980 steel under proportional loading were simulated with the dislocation density based microstructural hardening model DD_model and the Yld00-2d yield function with the initial value of the MK geometrical defect of 0.967 , an unusual $f_{0}$ value similar with the ones previously found in our study. As fig. 23 shows, a good agreement between theoretical and experimental forming limits is achieved. Continuing our analysis, the sharpness of the yield surface was described by two values of parameter "a" in Yld200-2d yield function, namely 6 and 5 . While $a=6$ it is observed a slight under evaluation of the predicted forming limits in the biaxial stretching region, which can be recovered by using $\mathrm{a}=5$. 


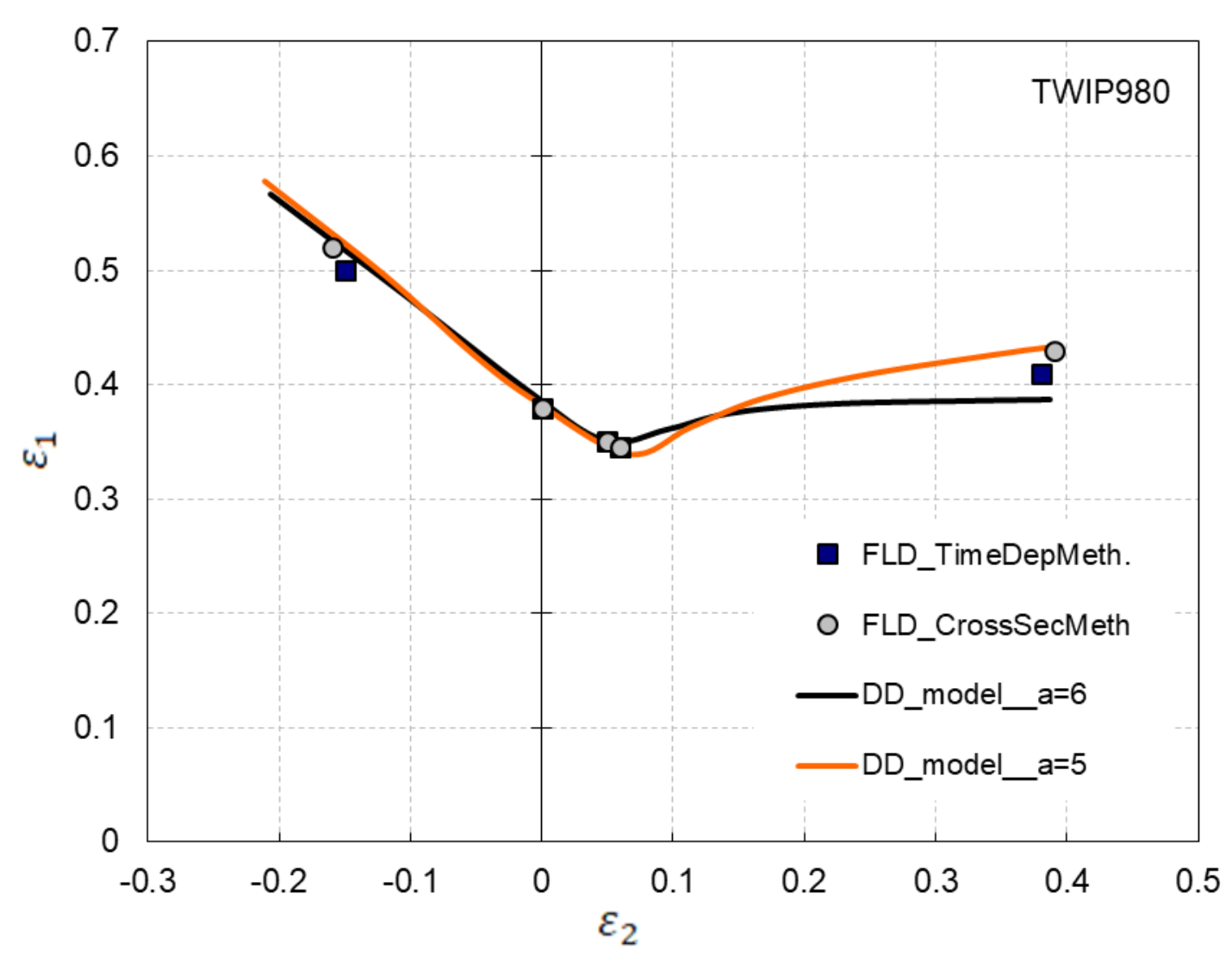

Fig. 23. Experimental and theoretical FLDs of TWIP980 steel sheet predicted by DD_model and Yld00-2d yield function

According to Kim et al (2013) the fraction of twinned grains was measured by EBSD as a function of true strain. Hence, the strain-dependent fraction of the twinned grains $f(\bar{\varepsilon})$ from Eq. 6 of the present dislocation based model, was fitted to a power law function:

$f(\bar{\varepsilon})=1.78(\bar{\varepsilon}-0.04)^{0.84}$

With the purpose of analyzing the influence of the twinned grains on the prediction of FLDs, the fraction of the twinned grains was expressed in a general way by using the coefficient $\mathrm{k}_{\mathrm{f}_{-} \mathrm{tg}}$, as Eq. 14 shows:

$f\left({ }^{-}\right)=\mathrm{k}_{\mathrm{f}_{\mathrm{tg}}}\left({ }^{-}-0.04\right)^{0.84}$

The fraction of the twinned grains was modified by reducing the value of $\mathrm{k}_{\mathrm{f}_{-} \mathrm{tg}}$ to 1 from 1.78 , the identified value for the selected TWIP980 steel. The evolution of the fraction of twinned grains with the strain is presented in Fig. 24, while the true stress-true strain curves are presented in Fig. 25. The decrease of the coefficient $\mathrm{k}_{\mathrm{f}_{\mathrm{t}} \mathrm{tg}}$ leads to a decrease of the fraction of the twinned grains and the true stress. Fig. 26 shows the effect of the fraction of the twinned 
grains on the FLDs of TWIP980 steel. The predicted FLD for $\mathrm{k}_{\mathrm{f}_{-} \mathrm{tg}}$ of 1 is much lower than the FLD obtained for $\mathrm{k}_{-} \mathrm{tg}$ of 1.78 . The decrease of the fraction of the twinned grains through the constant of the power-law function, which expressed it, allows to a decrease in the predicted forming limits. The formability decreases since the contribution of the twinned grains is reduced.

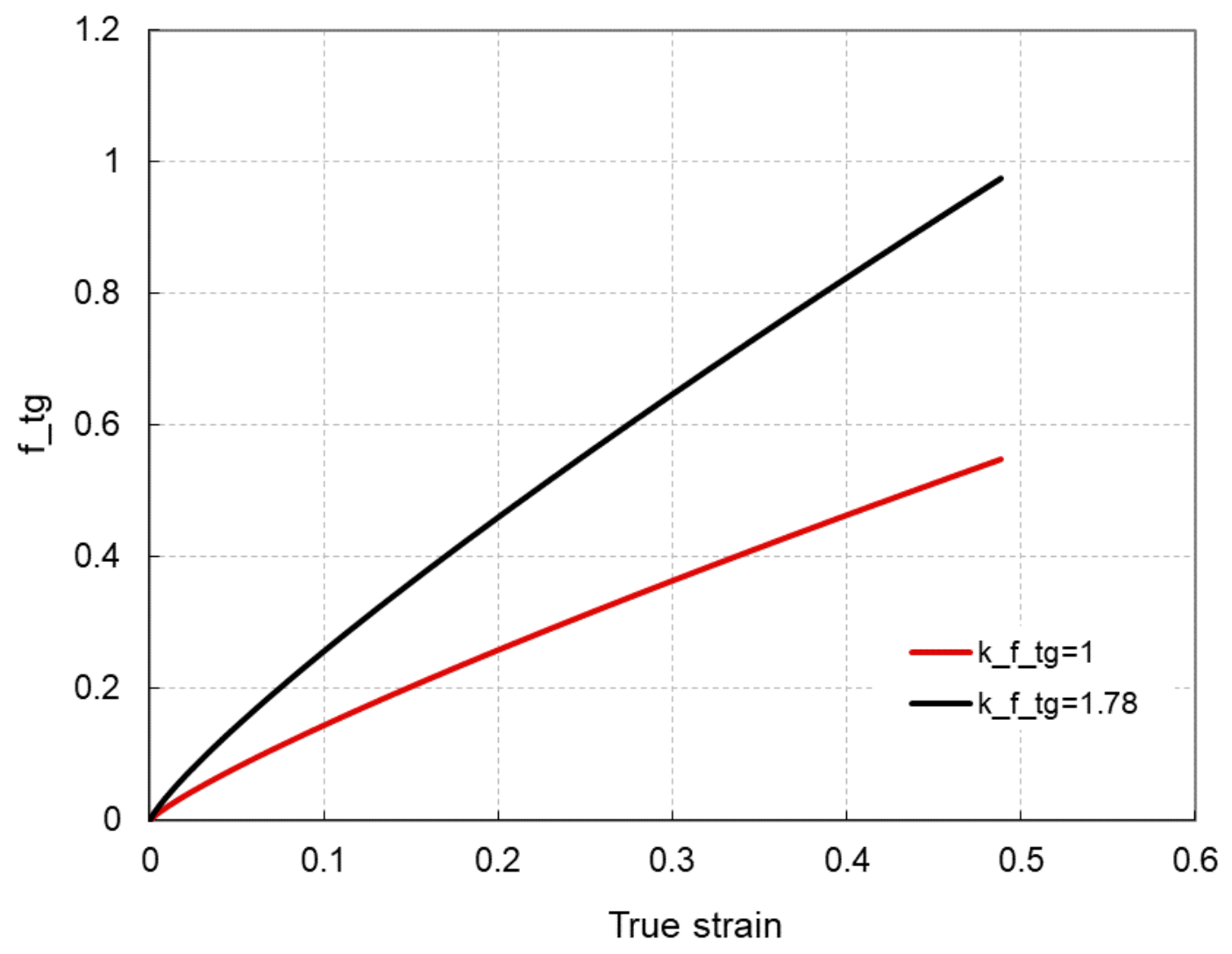

Fig.24. Evolution of the fraction of twinned grains with the strain while varying the constant of its power-law function 


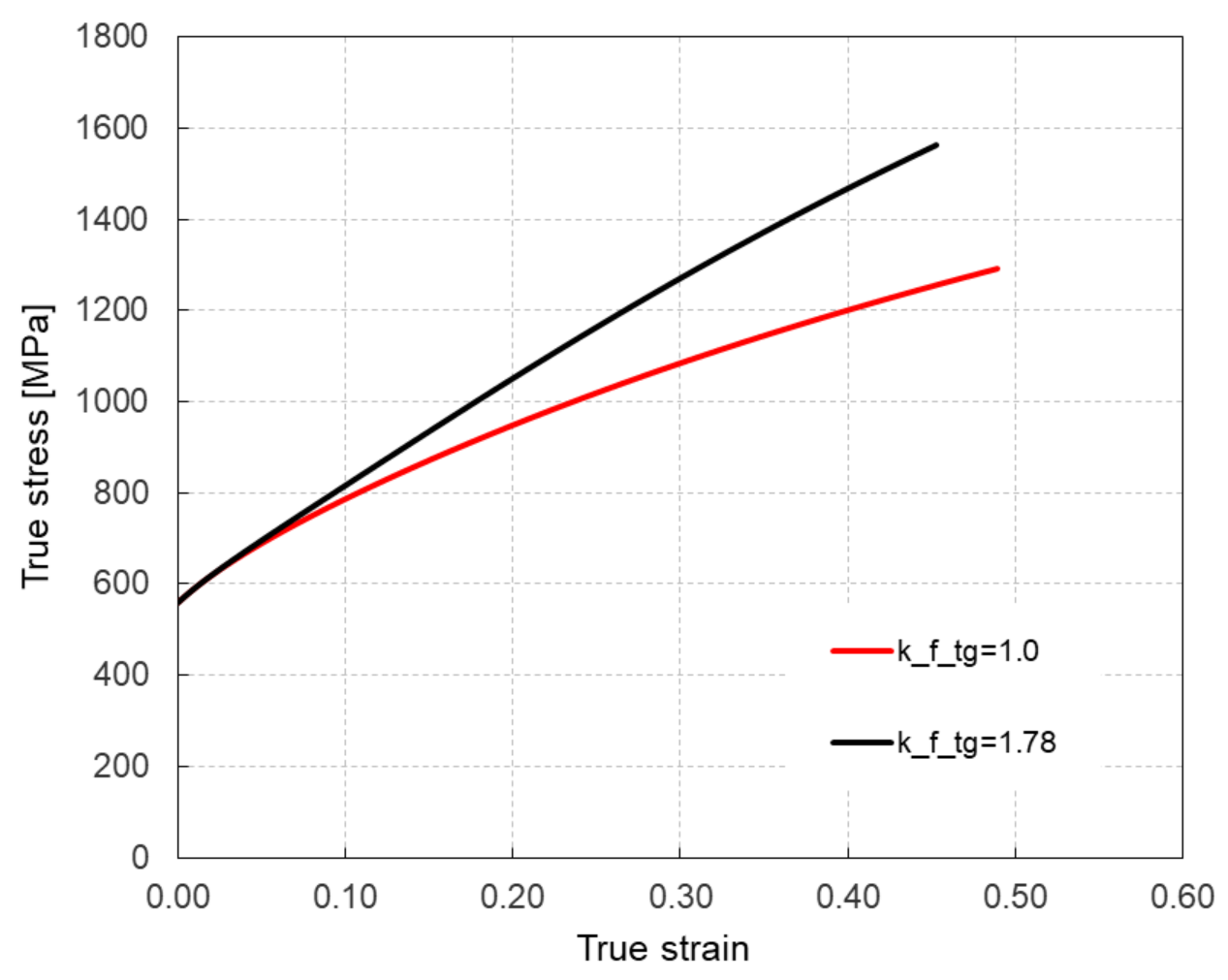

Fig.25. Influence of the fraction of twinned grains on true stress-true strain curves while varying the constant of the power-law function

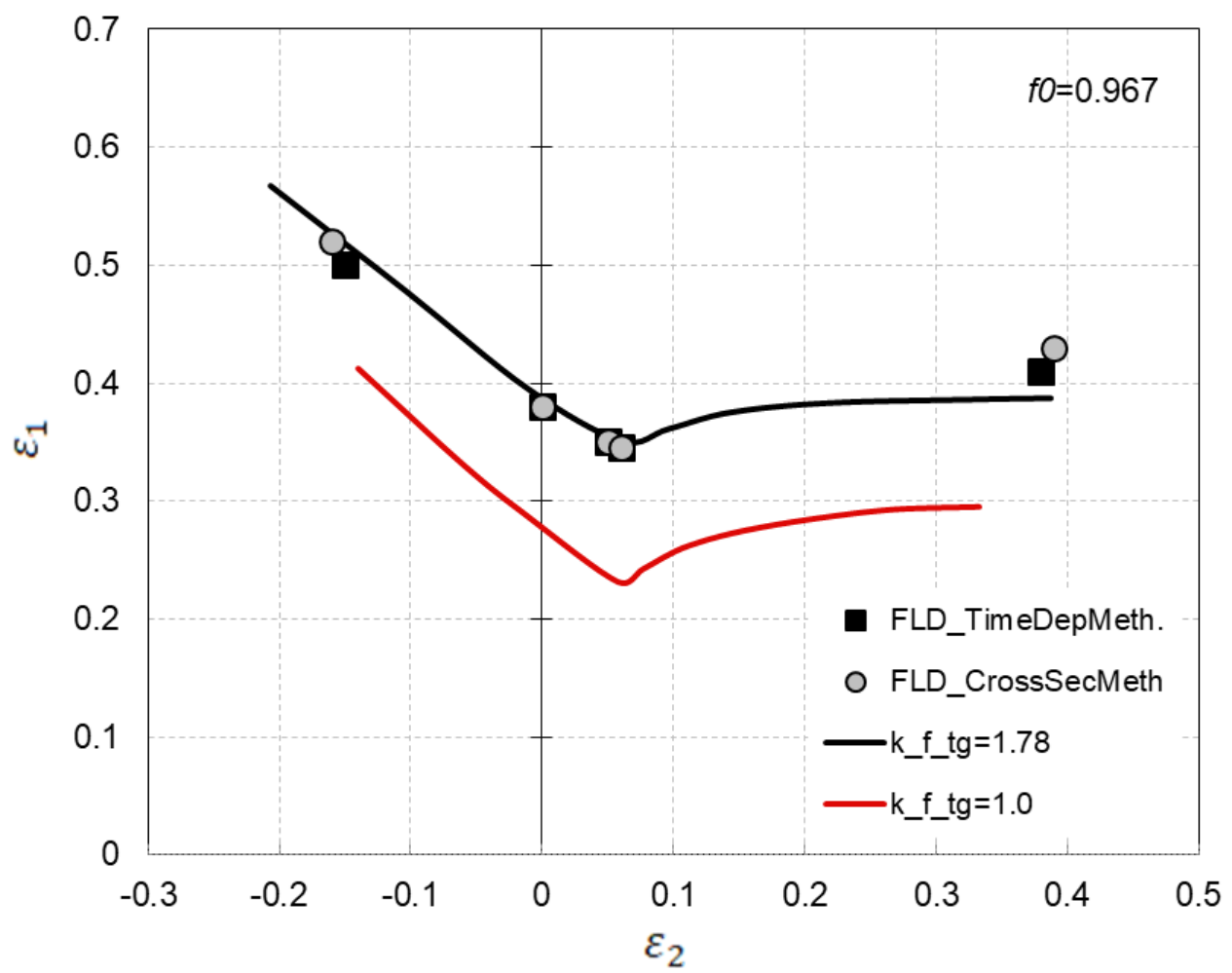

Fig. 26 The effect of the variation of the fraction of the twinned grains through the constant of its power-law function on the FLDs of TWIP steel 
Kim et al. (2013) introduced in their model the contribution of DSA to the flow stress by assuming that a dislocation will attract an atmosphere of carbon controlled by its bulk concentration and the dislocation-solute binding energy. Hence the flow stress was represented as an additive combination of the stress to overcome the localized obstacles associated with forest junctions and the stress stemming from additional pinning by carbon atmospheres. Hutchinson et al. (2006) and Shun et al. (1992) attributed the high strainhardening rate to dynamic strain aging (DSA) mechanisms, interpreted as the interaction between mobile dislocations and carbon atoms. Kim et al. (2007), Canadinc et al. (2008) and Renard et al. (2010) reported that localized deformation, which is related with DSA occurred in TWIP steel based on the observation of the negative strain rate sensitivity of the flow stress and a thermally activated character of plastic deformation. However, the exact natures of DSA and localized deformation are still under discussion. Using the DD_model, the contribution of dynamic strain aging to the FLDs of the TWIP980 steel is the next purpose of our study. The maximum contribution of the DSA to the flow stress mainly depends on the carbon-dislocation binding energy. Kim et al. (2013) estimated the maximum contribution of DSA to the flow stress to be less than 20MPa for the selected TWIP steel, using a dislocationcarbon interaction energy of $0.015 \mathrm{eV}$ (Blanter et al., 2000). In addition of this assumption it was considered for $\sigma_{\mathrm{DSA}}$ several values by varying $\chi$, the coefficient characterizing the strength of the dislocation-solute interaction. Fig. 27 shows the evolution of $\sigma_{\text {DSA }}$ with the strain for twin-free (acronym sdsaTF) and twinned grains (acronym sdsaT) for the TWIP980 steel, using $\chi$ of 10, 20, 27.5 and 35. The $\sigma_{\mathrm{DSA}}$ increases with the increase of the value of $\chi$. As seen from Fig. 27, $\sigma_{\mathrm{DSA}}$ for the twin-free grains is higher than for the twinned grains, due to the fact that twinned grains have a higher forest dislocation density than the twin-free ones (see Eq. 4 and Eq.5). 


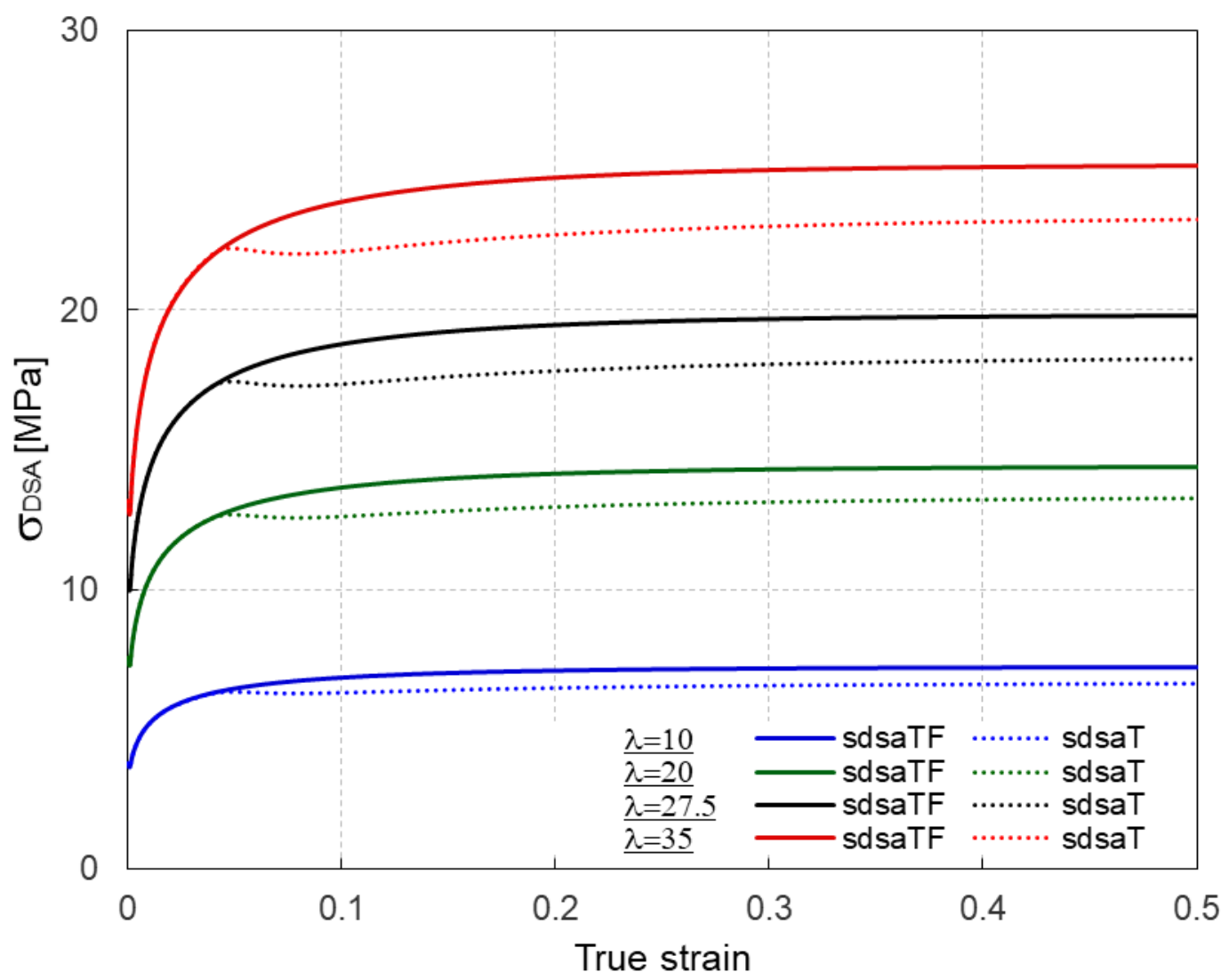

Fig. 27. Evolution of $\sigma_{D S A}$ with the strain for twin-free and twinned grains for TWIP980 steel

As Fig. 28 shows, the influence of $\sigma_{\mathrm{DSA}}$ on the flow stress for the TWIP980 steel is minor, corroborating the results of Kim et al. (2013), which found that this result is hinged on the choice of the value of the carbon dislocation binding energy, being consistent with the fact that the stress increment due to static strain aging has a minor influence in this material. The contribution of the DSA to the FLDs of TWIP980 steel is presented in fig 29, which shows the FLDs predicted with DD_ model and Yld00-2d using $\chi$ of 10, 20, 27.5 and 35. A slight but perceptible effect of $\sigma_{\mathrm{DSA}}$ on the predicted FLDs is noticed. The increase of the $\sigma_{\mathrm{DSA}}$ allows to a decrease of the predicted forming limits. So, the DSA of TWIP steel contributes to a soft decrease of their formability. 


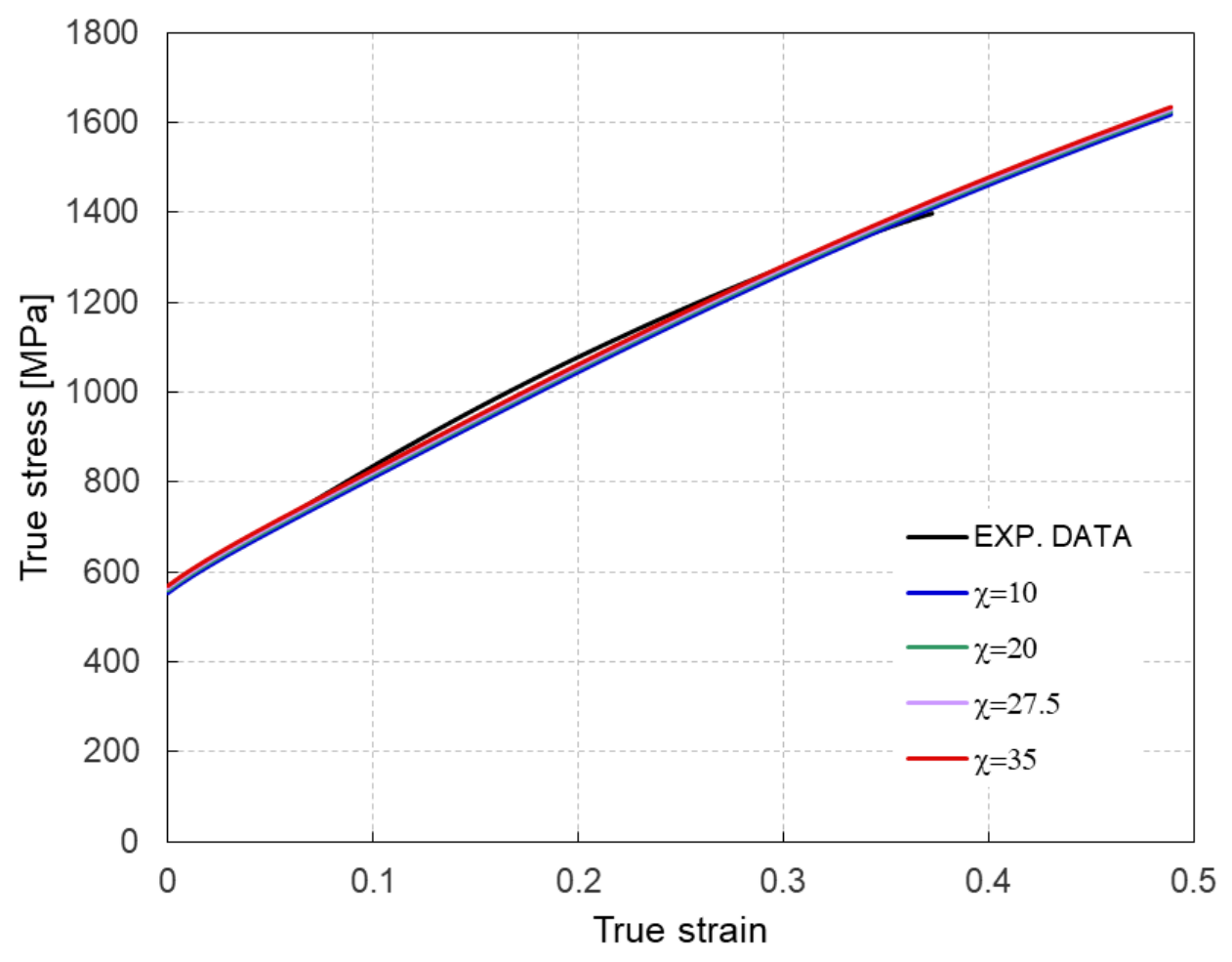

Fig. 28. The influence of $\sigma_{\mathrm{DSA}}$ on the true stress-true strain curve for TWIP980 steel

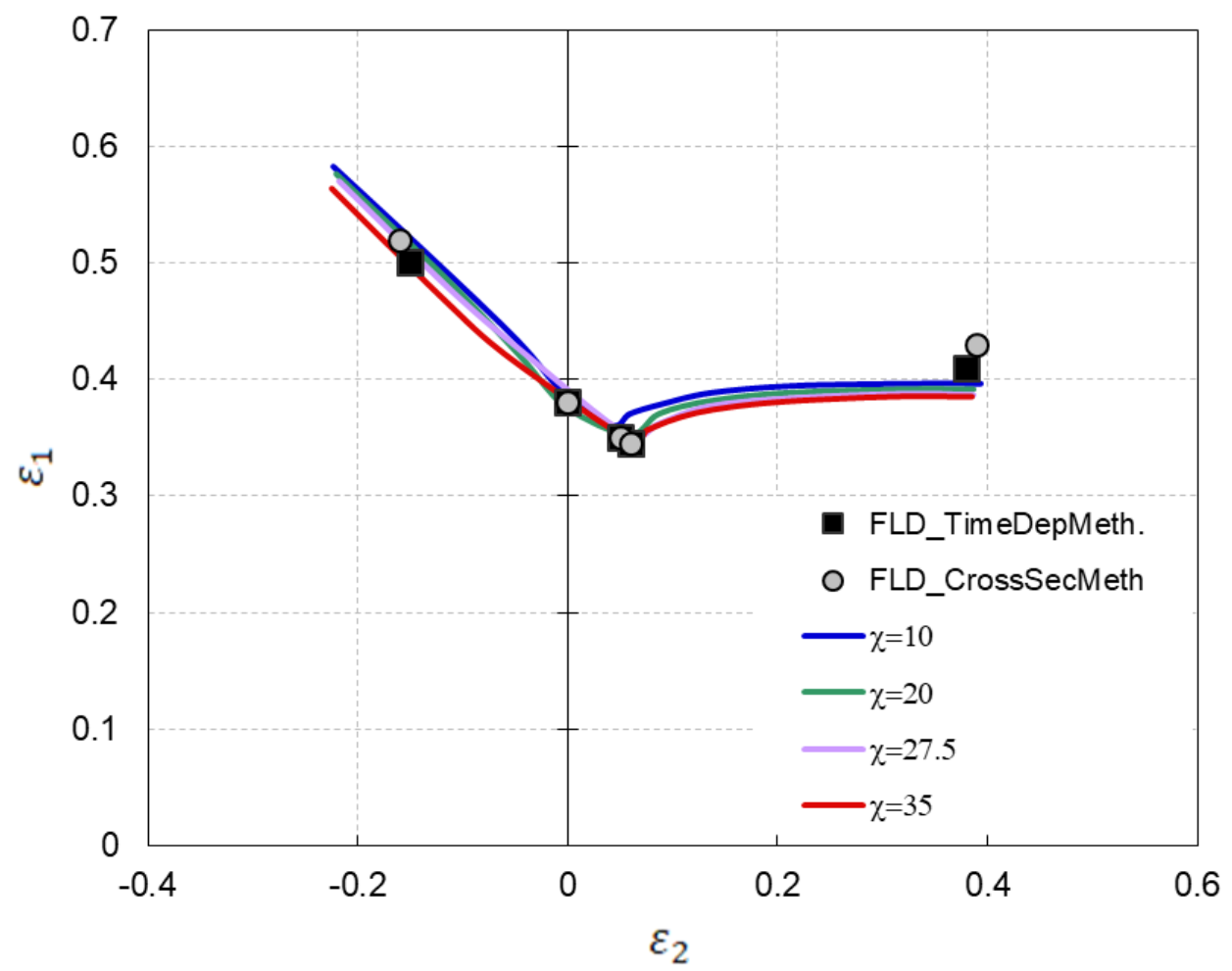

Fig. 29. The influence of $\sigma_{\text {DSA }}$ on the FLDs of TWIP980 steel 


\section{Conclusions}

The MK theory has been used to predict the forming limits for TWIP steel sheets under linear strain paths. The Yld00-2d condition (Barlat et al., 2003) combined with Swift strainhardening power law and the dislocation density based constitutive model proposed by Kim et al. (2013), respectively, were the constitutive model considered in the MK theory. With certain adjustments, a proper agreement between experimental and theoretical results for all selected materials was found. The accuracy on the prediction of the forming limits is due to the ability of the selected constitutive equations to describe the TWIP steels behavior.

Yld00-2d yield function accurately describes the TWIP steel behaviour playing a fundamental role in the accuracy of the forming limits prediction. The present analysis shows the great importance of the ability of the yield function to reproduce the sharpness of the yield surface in the biaxial stretching region for the correctness of the prediction of the FLDs, emphasizing also the key role of the correct identification of the parameters of the material. The exponent of the Yld00-2d yield function "a" of 5 was found to be more adequate for TWIP steel in predicting the FLD, on despite of the typical use of 6 or 8 for BCC and FCC materials. Anyway, the TWIP steel has an unusual behaviour since it has a FCC structure but according to $\mathrm{Xu}$ et all. (2012) it works better with "a" of 6 characteristic value of BCC materials. This fact promotes the possibility that the exponent "a" of the yield function is not connected essentially with the crystal structure, and more values beside of 6 and 8 should be explored specially in the case of new structural materials. It was also found that the evolution of the yield surface has no effect on the predicted forming limits of the TWIP steel, since its yield surface shape almost does not evolve during the deformation. A sensitive study on the effect of the mechanical properties of the TWIP steel on the predicted forming limits was performed. The formability of the TWIP steel can be improved by modifying certain

mechanical parameters of the material, especially increasing $\mathrm{R}_{0}$ and the strain rate sensitivity coefficient while decreasing the balanced biaxial yield stress.

Using the model proposed by Kim et al (2013) taking into account the dislocation glide, twinning, and dynamic strain aging (DSA), the effect of the twinning phenomenon and DSA to the FLDs of TWIP steel were analyzed. The contribution of the twinned grains, through the fraction of the twinned grains, allows to the increase of formability. The DSA of TWIP steel contributes to a slight decrease of their formability. 
For all applied constitutive equations, the MK theory seems to be able to predict the forming limits of TWIP steels only by introducing unusual high initial geometrical defects due to the high strain hardening of the TWIP steels and by the impossibility of taking into account the negative strain rate sensitivity.

In spite of all efforts, we are not able to obtain good FLD predictions of TWIP steels, unless imperfection factors that are not physically plausible are introduced in MK model. Therefore, this demonstrates that MK theory is not suitable for TWIP steel and new failure models are required for this type of materials.

\section{Acknowledgments}

The authors acknowledge support from the Operational Program for Competitiveness and Internationalization, in its FEDER/FNR component and the Portuguese Foundation of Science and Technology (FCT), in its State Budget component (OE) through projects POCI01-0145-FEDER-032466, UID/EMS/00481/2013 and CENTRO-01-0145-FEDER-022083.

\section{References:}

Allain, S., Chateau, J-P, Bouaziz, O., 2004. A physical model of the twinning-induced plasticity effect in a high manganese austenitic steel. Materials Science and Engineering A 387-389, 143-147.

Bandyopadhyaya, K., Shamik, B., Sajun Prasad, K., Lee, M-G., Kr. Panda, S., Lee, J., 2019. Improved formability prediction by modeling evolution of anisotropy of steel sheets. International Journal of Solids and Structures 156-157, 263-280.

Barata da Rocha, A., Barlat, F., Jalinier, J.M., 1984. Prediction of the forming limit diagrams of anisotropic sheets in linear and non-linear loading. Materials Science and Engineering 68, 151-164.

Barlat, F., Brem, J. C., Yoon, J. W., Chung, K., Dick, R. E., Lege, D. J., Pourboghrat, F., Choi, S. -H. Chu E., 2003. Plane stress yield function for aluminum alloy sheets. Part 1: theory. Int. J. Plasticity 19, 1297-1319.

Bintu A., Vincze, G., Picu, C.R., Lopes, A.B., Grácio, J.J., and Barlat, F., 2015. Strain hardening rate sensitivity and strain rate sensitivity in TWIP steels. Materials Science and Engineering A 629, 54-59.

Blanter, M. S., Golovin, I. S., De Batist, R., Golovin, S. A., 2000. Effect of plastic deformation on the carbon internal friction peak in austenitic steels. Physica Status Solidi A, 178, 621-632.

Bouaziz, O. and Guelton, N., 2001. Modelling of TWIP effect on work-hardening. Materials Science and Engineering A 319-321, 246-249.

Bouaziz, O., Allain S. and Scott, C., 2008. Effect of grain and twin boundaries on the hardening mechanisms of twinning-induced plasticity steels. Scripta Materialia 58, 484-487.

Butuc M.C., Barata da Rocha, A., Gracio, J.J., 2003. A theoretical study on Forming Limit Diagrams Prediction. Journal of Materials Processing Technology 142, Issue 3, 714-724.

Butuc, M.C., Teodosiu, C., Barlat, F., Grácio, J.J., 2011. Analysis of sheet metal formability through isotropic and kinematic hardening models. European Journal of Mechanics /A Solids 30, 532-546. doi: 10.1016/j.euromechsol.2011.03.005.

Butz, A., Zapara, M., Erhart, A., Croizet, D., Stenberg, N., Hagstrom, J., Helm, D., Schneider, M., Kampczyk, M., Haufe, A., Biasutti, M., 2014. Deformation behavior of twip-steels: from experiments to constitutive modelling and simulations, In: Sfar, H., Maillard, A. (Eds.), Proceedings of IDDRG 2014 Conference Innovations for the sheet metal industry, Paris, France, pp. 491-496. 
Canadinc, D., Efstathiou, C., Sehitoglu, H., 2008. On the negative strain rate sensitivity of Hadfield steel. Scripta Materialia, 59, 1103-1106.

Chung, K., Ahn, K., Yoo, D.-H., Chung, K.-H., Seo, M.-H., Park, S.-H., 2011. Formability of TWIP (twinning induced plasticity) automotive sheets. International Journal of Plasticity 27, 52-81.

Coll, A., 2000. Forming Limit Diagrams: A Survey. Proceedins of VII ${ }^{\text {th }}$ national conference on Technologies and Machine-Tools for Cold Metal Forming TPR2000, Cluj-Napoca, Romania, 29-51.

Kim, J.K., Chen, L., Kim, H.S., Kim, S.K., Estrin, Y., De Cooman, B.C., 2007. On the tensile behavior of highmanganese twinning-induced plasticity steel. Metallurgical and Materials Transactions A 40, Issue 13, 31473158.

De Cooman, B.C., Estrin, Y., Kim, S.K., 2017. Twinning-induced plasticity (TWIP) steels, Acta Materialia 142, 283-362. http://dx.doi.org/10.1016/j.actamat.2017.06.046

Estrin, Y. and Kubin, L.P.: Acta Metall., 1986. Local strain hardening and nonuniformity of plastic deformation. Acta Metallurgica 34, pp. 2455-64.

Goodwin, G.M. 1968. Application of Strain Analysis to Sheet Metal Forming Problems. In the Press Shop, Society of Automotive Engineers, technical paper no. 680093.

Habibi, N., Abbas, Z.-H., Abedi, H.-R., 2015. An investigation into the fracture mechanisms of twinninginduced-plasticity steel sheets under various strain paths. Journal of Materials Processing Technology 224, 102116. http://dx.doi.org/10.1016/j.jmatprotec.2015.04.014

Han, H.N., Kim, K.-H., 2003. A ductile fracture criterion in sheet metal forming process. Journal of Materials Processing Technology 142, Issue 1, 231-238. doi: 10.1016/S0924-0136(03)00587-9

Hecker, S.S., 1975. Simple Technique for Determining Forming Limit Curves. Sheet Metal Industries, 671-676.

Hutchinson, B. and Ridley, N., 2006. On dislocation accumulation and work hardening in Hadfield steel. Scripta Materialia 55, Issue 4, 299-302.

Hutchinson, J.W., Neale, K.W. and Needleman, A., 1978. Sheet Necking-I Validity of plane stress assumption of the long-wave length approximation. Mechanics of Sheet Metal Forming, eds. D.P. Koistinen and N.M. Wang, Plenum. Press, New York, 111-126.

Kang, J.-H., Ingendahl, T., Bleck, W., 2015, A constitutive model for the tensile behaviour of TWIP steels: Composition and temperature dependencies. Materials \& Design 90, 340-349

Keeler S.P. 1965. Determination of Forming Limits in Automotive Stampings. Society of Automotive Engineers, Technical paper No. 650535.

Kim, J., Estrin, Y. and De Coman, B.C., 2013. Application of a Dislocation Density-Based Constitutive Model to Al-Alloyed TWIP Steel. Metallurgical and Materials Transactions A: Physical Metallurgy and Materials Science 44, Issue 9, 4168-4182.

Kubin, L.P. and Estrin, Y., 1990. Evolution of dislocation densities and the critical conditions for the PortevinLe Chatelier effect. Acta Metall. Mater. 38, pp. 697-708.

Lian J., Barlat F., Baudelet B., 1989. Plastic behaviour and stretchability of sheet metals. Part II: effect of yield surface shape on sheet forming limit, Int. J. Plasticity, 5, 131-147.

Lian, J., Fuhui Shen, F., Jia, X., Ahn, D.-C., Chae, D.-C., Münstermann, S., Bleck, W., 2018. An evolving nonassociated Hill48 plasticity model accounting for anisotropic hardening and r-value evolution and its application to forming limit prediction. International Journal of Solids and Structures 151, 20-44.

Lou, Y., Huh, H., Lim, S. and Pack, K., 2012. New ductile fracture criterion for prediction of fracture forming limit diagrams of sheet metals. International Journal of Solids and Structures 49, 3605-3615. doi:10.1016/j.ijsolstr.2012.02.016

Marciniak, Z., Kuczyski. K., 1967. Limit strains in the processes of stretch-forming sheet metal, Int. J. Mech. Sciences 9, 609-620.

Marciniak, Z., Duncan, J.L., Hu, S.J., 2002. Mechanics of sheet metal forming, publisher, Oxford, Boston, Butterworth-Heinemann. 
McCarron, T.J., Kain K.E., Hahn, G.T. and Flanagan, W.F., 1988. Effect of geometrical defects in forming sheet steel by biaxial stretching. Metallurgical transactions. A, Physical metallurgy and materials science 19 A(8), 2067-2074.

Nurcheshmeh, M. and Green, D.E., 2016. Prediction of forming limit curves for nonlinear loading paths using quadratic and non-quadratic yield criteria and variable imperfection factor. Materials\&Design 91, 248-255. https://doi.org/10.1016/j.matdes.2015.11.098

Renard, K., Ryelandt, S., Jacques, P.J., 2010. Characterisation of the Portevin-Le Châtelier effect affecting an austenitic TWIP steel based on digital image correlation. Materials Science and Engineering A 527, 2969-2977.

Shun, T.S., Wan, C.M. \& Byrne, J.G., 1992. A study of work hardening in austenitic Fe-Mn-C and Fe-Mn-Al-C alloys. Acta. Metall. Mater. 40-12, 3407-3412.

Stachowicz, F., 1988. Effect of annealing temperature on plastic flow properties and forming limits diagrams of titanium and titanium alloy sheets. Trans. Jpn. Inst. Metals 29, 484-493.

Stoughton, T. B. and Zhu, X., 2004. Review of theoretical models of the strain-based FLD and their relevance to the stress-based FLD, International Journal of Plasticity 20, Issues 8-9, 1463-1486.

Vinogradov, A., Vasilev, E., Merson, D., Estrin, Y., 2017. Phenomenological Model of Twinning Kinetics. Advanced Engineering Materials 19, Issue 1, Article number 1600092, 1-10.

Xu, L. and Barlat, F., 2011. Macroscopic constitutive modeling of a TWIP steel sheet sample. The 1st International Conference on High Manganese Steels, Grand Hilton, Seoul, Korea, May 2011, 1-8.

Xu, L., Barlat, F., Lee, M.-G., 2012. Hole expansion of twinning-induced plasticity steel. Scripta Materialia 66, Issue 12, 1012-1017.

Yoshida, K., Abe, K., Miyauchi, K. And Nakagawa, T., 1968. Instability and fracture behaviour in sheet metal forming. IDDRG, La Metallurgia Italiana, 8. 